
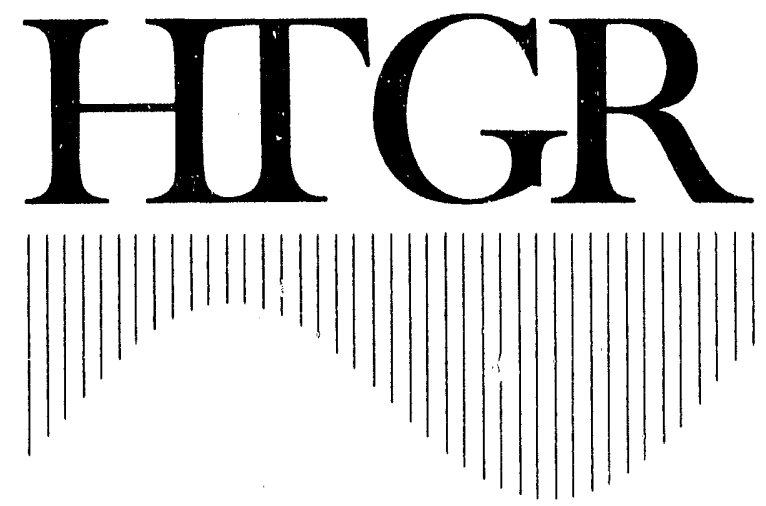

\title{
MHTGR PRODUCT DISTINCTION
}

ISSUED BY GAS-COOLED REACTOR ASSOCIATES 


\section{DISCLAIMER}

This report was prepared as an account of work sponsored by :n agency of the United States Government. Neither the United States Government nor any agency thereof, nor any of their employees, makes any warranty, express or implied, or assumes any legal liability or iesponsibility for the accuracy, completeness, or usefulness of any information, apparatus, product, or process disclosed, or represents that its use would not infringe privately owned rights. Reference herein to any specific commercial product, process, or service by trade name, trademark, manufacturer, or otherwise does not necessarily constitute or imply its endorsement, recommendation, or favoring by the United States Government or any agency thereof. The views and opinions of authors expressed herein do not necessarily state or reflect those of the United States Government or any agency thereof

Issued by: Gas-Cooled Reactor Associates Under Contract to the U.S. Department of Energy

Contract No. DE-AC03-90SF 18758

December, 1990 
CONTENTS

PAGE

1.0 INTRODUCTION . . . . . . . . . . . . . . . . $1-1$

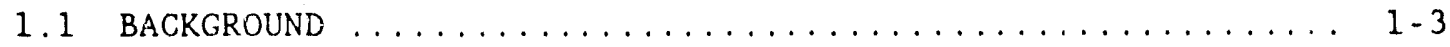

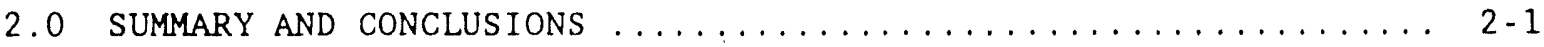

2.1 SUMMARY OF THE BENEFITS OF PRODUCT DISTINCTION $\ldots \ldots \ldots \ldots, 2-1$

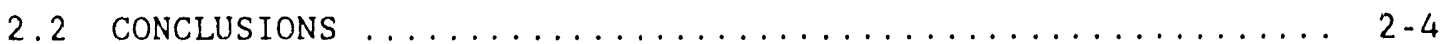

3.0 SUMMARY OF CURRENT GENERATION NUCLEAR PLANT ISSUES $\ldots \ldots \ldots \ldots \ldots 3-1$

4.0 MHTGR DISTINCT FEATURES AND DESIGN ATTRIBUTES $\ldots \ldots \ldots \ldots \ldots \ldots \ldots$ 4-1

4.1 CHARACTERISTICS ARISING FROM DIVERSE TECHNOLOGY ......... 4-1

4.2 PASSIVE FEATURES TO LIMIT ACCIDENT RESPONSE .......... $4-4$

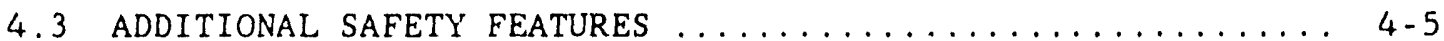

4.4 SAFETY AND LICENSING PERFORMANCE CHARACTERISTICS $\ldots \ldots \ldots \ldots$ 4-6

5.0 QUANTIFICATION OF PRODUCT DISTINCTION BENEFITS $\ldots \ldots \ldots \ldots \ldots \ldots .5$

5.1 COMPARISON OF SAFETY RELATED SYSTEMS AND STRUCTURES ...... $5-1$

5.2 COMPARISON OF TECHNICAL SPECIFICATIONS $\ldots \ldots \ldots \ldots \ldots \ldots \ldots .5-5$

5.3 QUANTIFICATION OF AVOIDED RISKS $\ldots \ldots \ldots \ldots \ldots \ldots \ldots \ldots \ldots .5 .5$

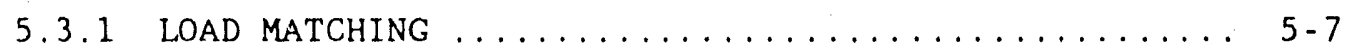

5.3 .2 COMMERCIAL OPERATION DELAYS ............... 5-8

5.3 .3 ROLE OF THE OPERATOR ................. 5-9

5.3 .4 EMERGENCY PLANNING ................... 5-10

5.3 .5 REGULATORY REQUIREMENTS SIMPLIFICATION ........ 5-12

5.3 .6 STANDARDIZED, AUTOMATED OPERATING SYSTEMS ....... 5-13

5.4 SUMMARY OF AVOIDED COST $\ldots \ldots \ldots \ldots \ldots \ldots \ldots \ldots \ldots \ldots \ldots \ldots \ldots \ldots \ldots \ldots \ldots, 14$

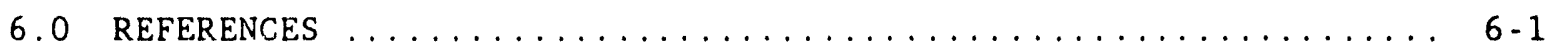

APPENDIX A TECHNICAL SPECIFICATION COMPARISON $\ldots \ldots \ldots \ldots \ldots \ldots \ldots \ldots$ A-1

A.1 SAFETY LIMITS AND LIMITING SAFETY SYSTEM SETTINGS $\ldots \ldots \ldots \ldots$ A-2

A. 2 LIMITING CONDITIONS OF OPERATION $\ldots \ldots \ldots \ldots \ldots \ldots \ldots \ldots$ A-3

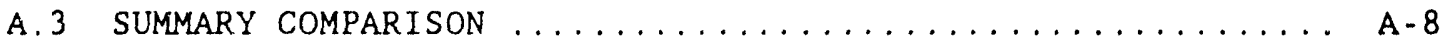

APPENDIX B UNIT SIZE AND CONSTRUCTION SCHEDULE EFFECT ON UTILITY LOAD MATCHING $\ldots \ldots \ldots \ldots \ldots \ldots \ldots \ldots \ldots \ldots \ldots \ldots$ 


\section{LIST OF ILLUSTRATIONS}

\section{FIGURE}

PAGE

3-1 CURRENT GENERATION NUCLEAR PLANT COMMERCIAL OPERATION DELAYS . 3-2

3-2 TYPICAL PLANT STAFF SIZE COMPARISON $\ldots \ldots \ldots \ldots \ldots \ldots \ldots \ldots, 3-2$

4-1 CORE HEAT CAPACITY COMPARISON $\ldots \ldots \ldots \ldots \ldots \ldots \ldots \ldots \ldots \ldots$.

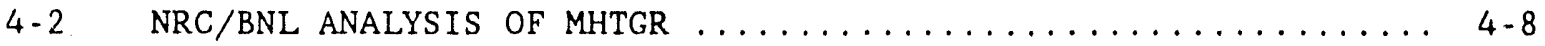

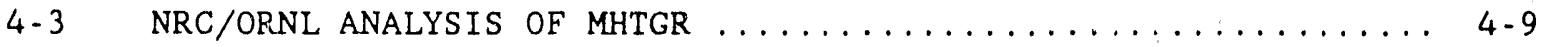

B-1 LOAD MATCHING - $2500 \mathrm{MW}$ (e) SYSTEM, 140 vs $1000 \mathrm{MW}(\mathrm{e}) \ldots \ldots \ldots$ B-7

B-2 LOAD MATCHING - $2500 \mathrm{MW}$ (e) SYSTEM, 140 vs $560 \mathrm{MW}($ e $) \ldots \ldots \ldots$ B-8

B-3 LOAD MATCHING - $10000 \mathrm{MW}($ e) SYSTEM, 140 vs $1000 \mathrm{MW}($ e) $\ldots \ldots$ B-9

B-4 LOAD MATCHING - $10000 \mathrm{MW}($ e) SYSTEM, 140 vs $560 \mathrm{MW}(\mathrm{e}) \ldots \ldots \ldots$. . 10

\section{LIST OF TABLES}

TABLE

$\underline{\text { PAGE }}$

2-1 TECHNICAL SPECIFICATION COMPARISON SUMMARY $\ldots \ldots \ldots \ldots \ldots \ldots \ldots$

$2-2$ SUMMARY OF ESTIMATED AVOIDED COSTS $\ldots \ldots \ldots \ldots \ldots \ldots \ldots \ldots \ldots$

5-1 COMPARISON OF SAFETY-RELATED SYSTEMS AND STRUCTURES $\ldots \ldots \ldots$ 5-2

5-2 TECHNICAL SPECIFICATION COMPARISON SUMMARY $\ldots \ldots \ldots \ldots \ldots \ldots \ldots$

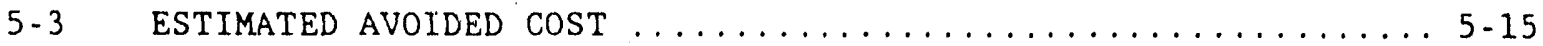

A-1 LIMITING CONDITIONS OF OPERATION COMPARISON $\ldots \ldots \ldots \ldots \ldots \ldots$ A -4

B-i UNIT SIZE/SCHEDULE EFFECT ON LOAD MATCHING TYPICAL RESUITS ......................... B-5

B-2 UNIT SIZE/SCHEDULE EFFECT ON LOAD MATCHING PENALTY $\ldots \ldots \ldots \ldots$ B-6 
SECTION 1

INTRODUCTION

Coal and nuclear power plants have been widely viewed as the primary near term (through the early 21 st century) options for U.S. baseload electric generation based on the domestic abundance of the fuel resources and their relative unsuitability for transportation (which is primarily served by oil and, potentially, gas). However, this view is far from universal, as illustrated by a recent report by the California Energy Commission (Reference 1-1), which makes only limited mention of coal and no mention of nuclear as a future energy option. Nuclear power must overcome a number of substantial barriers before it would be generally accepted as a viable future energy option.

With regard to future new coal-fired generation, there has been a growing recognition and concern regarding air quality deterforation and the potential for global climate change, considered to be driven in part by emissions from fossil-fired power plants. This is resulting in increased concern, on a global basis, regarding primary reliance on fossil fuels for future energy generation. On the other hand, "local" (i.e., individual utility) experience with coal-fired plants has been generally positive, as reflected in a trend of decreasing production cost (fuel, operation and maintenance).

Concerns regarding air quality, global climate change and increasing dependence on foreign oil are causing a resurgence of interest in nuclear power on a global basis, although tempered by continuing concern regarding safety and the disposal. of nuclear waste. However, "local" experience with current generation nuclear power plants has been and continues to be segative in many instances. Since decisions to add new capacity are made on a "local" basis, a near term (i.e., by the turn of the century) revival of nuclear plant orders is far from certain. In the face of such uncertainty, it is advisable to maintain a diversity of options. 
In order to serve as a viable future energy option, an advanced nuclear plant must be accepted by two key groups: (1) the public, and (2) plant owners and investors. In considering nuclear power, the public thinks primarily in terms of:

- Perceived safety of the plant

- Waste disposal (including daily discharges, spent fuel, and decommissioning)

- Cost of power (with particular sensitivity to rate changes)

In considering the purchase of a plant, owners and investors think primarily in terms of:

- Return of and return on investment

- Downside risks associated with $O \& M$ cost escalation, plant closures, regulatory pressures, etc.

Much of the current market resistance to new nuclear plants is considered to evolve from current perceptions among potential owners and investors of the downside risk, as projected based on current experience. The MHTGR design is being developed to present a distinct approach to containing these risks.

Commercial power reactor operating experience and regulatory practice in the United States is dominated by Light Water Reactor (LWR) technology. This experience base and regulatory structure is a point of departure for the development of any future nuclear option, and must be understood and utilized as appropriate. This report discusses experience with current generation plants considered xelevant to MHTGR development, as well as the fundamental differences between the MHTGR and LWR technology, and quantifies avoided business risks relative to current generation plants. It does not attempt to compare the MHTGR with other advanced nuclear options, LWR or other technologies, which are also under development and must relate to the historical framework in accordance with their own unique characteristics. 


\subsection{BACKGROUND}

The owners of current generation nuclear plants are confronted with technical and management issues that remain a source of ongoing uncertainty and business risk (Reference 1-2). Much of the uncertainty stems from the processes required of industry to assure public health and safety to the satisfaction of regulatory authorities. All advanced reactor concepts under development in the U.S. seek to reduce the complex and exacting demands that have been placed on industry to license and operate the plants currently in operation. It is important that current plant experience be interpreted and applied in the specific context of a given concept.

The major benefits of nuclear electricity generation arise from the extremely small quantities of fuel required, as well as the very low release of effluents to the environment, relative to fossil fuel options. The major challenges arise from the buildup of a substantial inventory of highly radioactive materials, which must be contained at all times, and the inability to completely terminate power generation under accident conditions (decay heat). The MHTGR use of coated particle fuel and passive design features are explicitly directed toward addressing these challenges.

From the inception of the MHTGR concept to its selection as the reference design for development of HTGR technology in the U.S., it was recognized to represent a unique approach to commercial nuclear electricity generation. The MHTGR uses a radionuclide containment system that relies on passive systems to limit the challenges imposed on the primaxy fission product barrier, the fuel particle coating, and that provides multiple release barriers to meet the site boundary dose requirements. The five principal barriers are: (1) the fuel kernels, (2) the fuel particle coatings, (3) the core graphite, (4) the primary coolant pressure boundary, and (5) the reactor building. Of these barriers, the particle coating is the most important. This approach to fission product containment is expected to shift regulatory emphasis from the plant to the fuel. In doing so, it will reduce reliance on plant systems; and therefore the business 
risks associated with the intense regulatory purview of plant design, construction, operation and maintenance experienced during deployment of the first generaton of nuclear plants. It constitutes the MHTGR's most fundamental product distinction.

The application of HTGR technology to achieve a configuration that would meet the above objectives was understood by HTGR Program participants to limit the achievable power output per module. The thermal rating of the MHTGR was initially established as 350 MWt, compared with a rating of 842 MWt for the Fort St. Vrain HTGR, and up to 3800 MWt for later commercial plants (subsequeritly cancelled). The larger HTGR plants employed a design philosophy with regard to the use of active systems that is similar to the one used in the vast majority of current generation plants and for which current regulatory practices have evolved. In the development of the MHTGR, the presumption has benn that savings derived from the reduction of regulatory involvement and simplification of the design, construction, and operation of the MHTGR will offset the cost impact of smaller unit size. 
SECTION 2

SUMMARY AND CONCLUSIONS

Light Water Reactor (LWR) technology dominates the current generation of nuclear plants worldwide. Because of the broad experience gained with LWRs, developing future LWR options based on this experience is clearly app opriate. Future LWR designs are addressing the problems experienced by current generation plants within the framework of the LWR technology and experience base. However, maintaining a diversity of options is clearly advisable as a prudent policy, in light of the vital importance of adequate electricity supplies and the formidable problems facing any future nuclear option.

HTGR technology offers the potential for uniquely different design characteristics and capabilities. A particular example is the capability of the MHTGR to lose primary coolant indefinitely without release of radionuclides from the fixel. The fundamental differences in fuel and systems characteristics between HTGR and LWR technology have been factored into the MHTGR approach to the solution of problems with current plants. Thus the MHTGR presents a substantially different ownership risk profile relative to current plants, and is expected to retain important differences with advanced LWRs. Because the advanced LWR designs are evolving, this section does not compare the MHTGR with advanced LWRs, but rather addresses distinctions with current generation plants. The diversity offered by these MHTGR distinctions, in confunction with large uncertainties in the future plant deployment environment, provides a basis for the continu ' development of the MHTGR in parallel with advanced LWRs.

\subsection{SUMMARY OF THE BENEFITS OF PRODUCT DISTINCTION}

Section 3 discusses issues associated with current generation nuclear plant operating experience that must be addressed by future plants. Section 4 discusses unique design attributes and safety and 1icensing 
performance characteristics associated with the MHTGR in the context of addressing current plant issues. In addition, a quantification of the anticipated benefits arising from attributes that define MHTGR product distinction is presented in section 3. The following is a summary of key points:

- The number of different safety related systems and structures is lower for the MHTGR than the comparison PWR, an indication of potential for simplification of regulatory requirements. Of equal or perhaps greater importance in this regard, MHTGR systems do not impose large electrical loads, rapid response, and precise time sequencing to the extent required in current plants

- A comparison of Technical Specifications for a current generation LWR, Fort St. Vrain, and an initial projection of Technical Specification requirements for the MHTGR shows the total number of Safety Limits, Limiting Safety System Settings, and Limiting Conditions of Operation (LCOS), to be about equal (Table 2-1). However, there are substantial differences in the cost and risk of compliance among the requirements. For example, a single LCO on the Emergency Core Cooling System for an LWR can address multiple redundant sets of pumps, valves, heat exchangers, etc., requiring much more effoxt than an LCO on, for example, control rod drop time. In general, because they apply mostly to passive systems, the effort required by individual MHTGR Technical Specifications is expected to be considerably lower. Another very significant factor is the much smaller number of unique Technical Specifications for the MHTGR, only 34 versus 118 for the PWR. This can substantially reduce training requirements and increase the efficiency of compliance.

- Risks and incurred costs experienced in the deployment of the current: generation of nuclear plants and expected to be avoided by the MHTGR are quantified in terms of avoided busbar cost of electricity for the following issues: 
Table 2-1

TECHNICAL SPECIFICATION COMPARISON SUMMARY

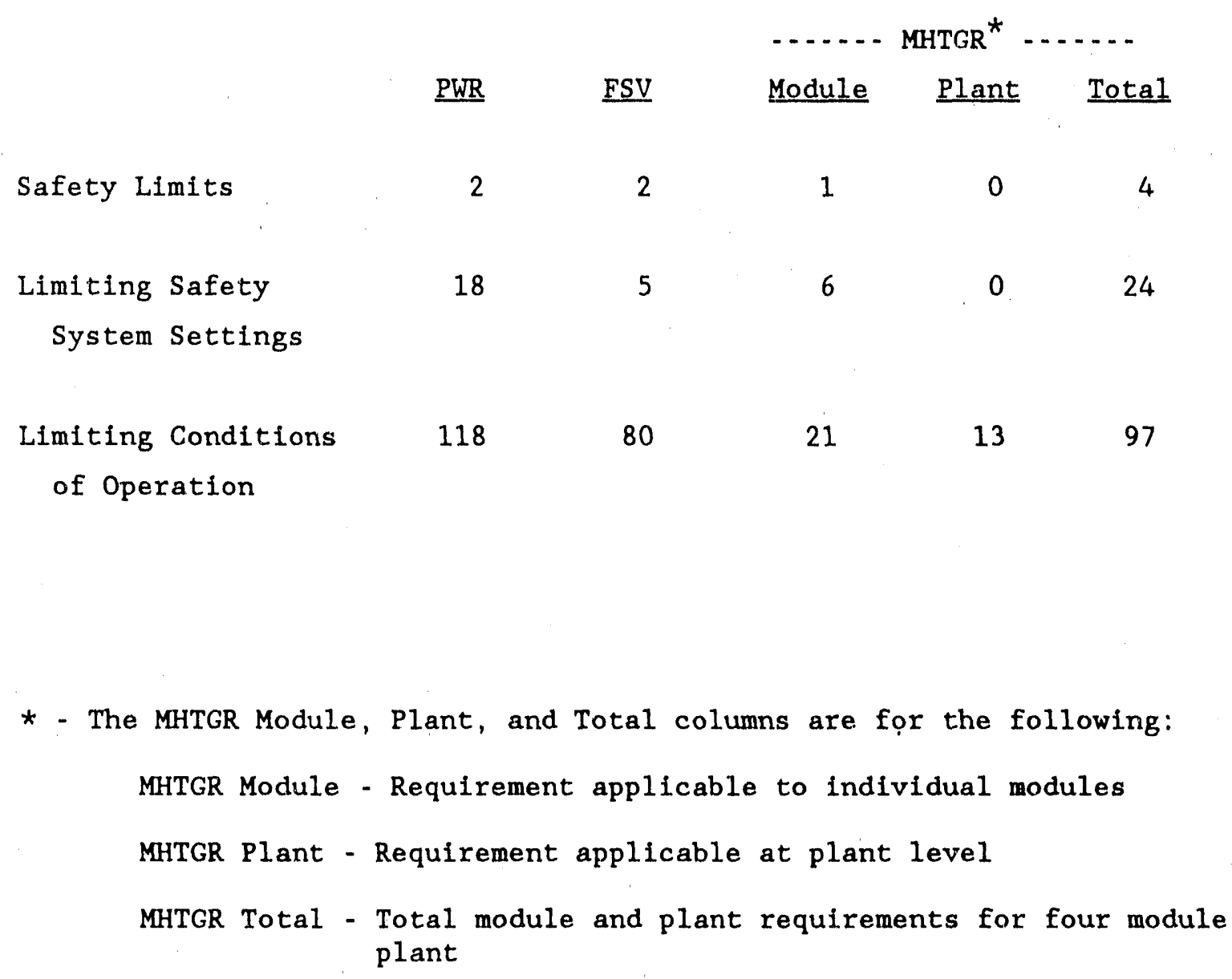


- Load Matching

- Construction Completion Delays

- Role of the Operator

- Emergency Planning

- Regulatory Requirements Simplification

- Operational Management Systems

The results are summarized in Table 2-2. They are considered only crude approximations in most cases, with errors of a factor of two or more easily possible. However, the bottom line of total avoided costs of the order of 20 to $50 \mathrm{Mills} / \mathrm{kWh}$ is an indication of the benefits of the MHTGR approach which act to offset lost benefits from economies of scale.

\subsection{CONCLUSIONS}

At present, the evaluated power cost estimate for the MHTGR is in the range of $50 \mathrm{Mills} / \mathrm{kWh}(190 \$)$. The avolded cost of $35 \mathrm{Mills} / \mathrm{kWh}$ would represent a very large increase in power costs if the expecter benefits of the MHTGR approach did not materialize. On the other hand, it is the potential for overcoming economies of scale penalties relative to larger plants, and reducing the risks of ownership, by providing these benefits which makes the MHTGR a viable future option. In considering these results, it must be recognized that the avoided costs identified in the previous section were developed in a subjective manner in the context of nuclear experience to date. However, the magnitude of the overall total of $35 \mathrm{Mills} / \mathrm{kWh}$ is considered generally valid. Whether the total is 20 or 50 Mills/kWh, the following conclusions remain valid:

- Substantial changes relative to the current nuclear plant operational environment are a necessary condition for a future nuclear option.

- Significant changes in future plant features and operational characterictistics are likely to be necessary in addition to the changes in the environment noted above. 
TABLE 2-2

SUMMARY OF ESTIMATED AVOIDED RISKS*

Topical Area

Load Matching

Construction Completion Delays

Role of the Operator

Emergency Planning

Regulatory Requirements Simplification

Operational Management Sy'stems
Mills/sWh

3

3

2

4

16

7

35

*Expressed as avoided busbar cost of electricity. 
- The MHTGR embodies a distinctly diverse approach to addressing the problems of current plants.

- The potential benefits of MHTGR differences are approximately quantifiable in terms of avolded costs and risks experienced by current plants.

- Large uncertainties in the future electricity generation economic and regulatory environment favor maintaining a diversity of future options.

The risk avoidance characteristics addressed in this report constitute a substantial positive factor in the consideration of the MHTGR as an option for future electricity generation. 
DOE - HTGR -88537

SECTION 3

SUMMARY OF CURRENT GENERATION NUCLEAR PLANT ISSUES

There have been many positive aspects of current generation plant experience, and continued operation of the plants will be of great value to both the economy and the environment in the U.S. However, further development of nuclear power in the near term faces substantial barriers, as evidenced by the general absence of the nuclear option from U.S. utility future generation plans. The following discussion sumarizes experience with current generation nuclear plants that indicate a need for changes in future plant design, licensing, construction and operating environment.

- Plant Commercial Operation Delays - The experience with current generation U.S. nucl ar plants is illustrated in Figure 3-1, showing the delay in commercial operation as a function of the originally scheduled date of first commercial operation. The data, taken from a 1987 report published in Nuclear News (Reference 3-1), show an average delay of 55 months.

- Operation and Maintenance Cost - Operation and maintenance costs at current generation nuclear plants have increased at a rate much greater than inflation, resulting in production (fuel + O\&M) costs exceeding costs for coal plants for the first time in 1987. As recently reported in Reference 3-2, the increases in operation and maintenance costs are being led by increases in staffing. Figure 3-2 illustrates the magnitude of the difference in typical plant staff size between current coal and nuclear plants. Since it has been generally accepted that nuclear plant capital costs will exceed coal plant capital costs, an advantage in production costs is essential to the economic viability of the nuclear option. 


\section{FIGURE 3-1 CURRENT GENERATION NUCLEAR PLANT Commercial Operation Delays}

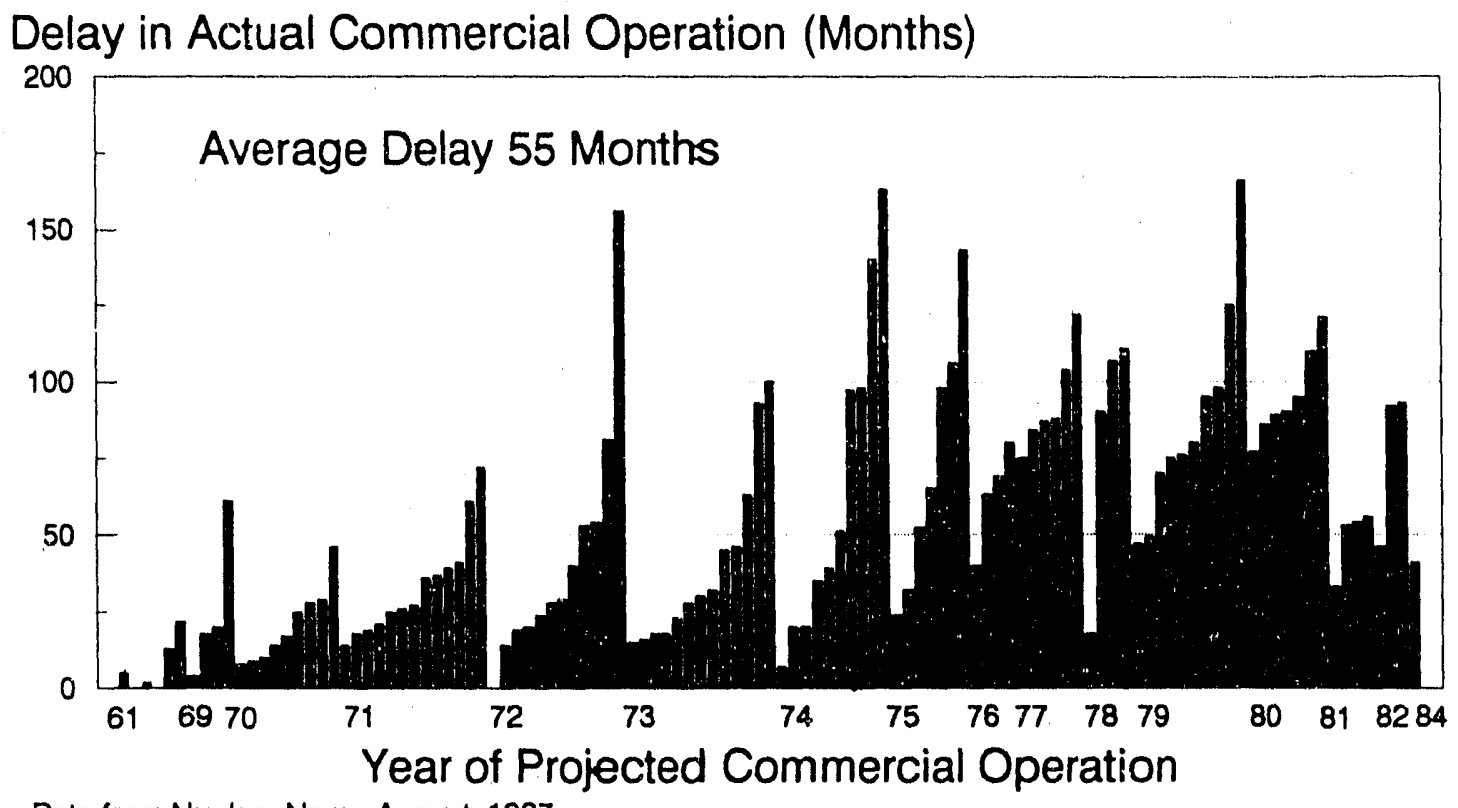

Date from Nuclear News, August, 1987

\section{FIGURE 3-2 TYPICAL PLANT STAFF SIZE COMPARISON Current Generation Coal and Nuclear}

\section{Total Plant Staff}

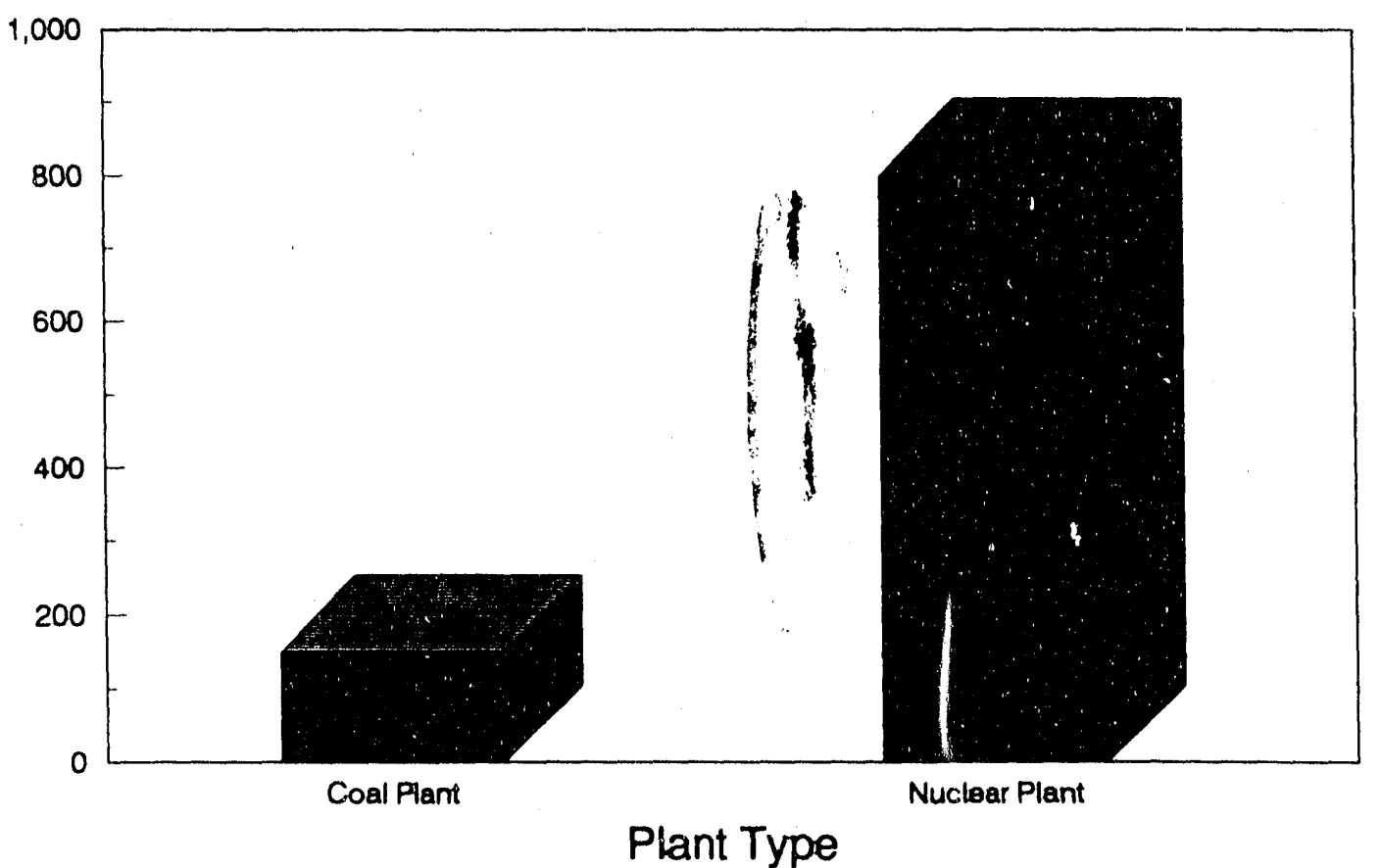

Nominal Typical Staff Sizes 
- Operational Regulatory Requirements - The extent of regulatory review and oversight experienced by a nuclear plant is considered to be a major factor in increasing operation and maintenance costs. A Working Group of experienced operations personnel (both fossil and nuclear) frcm GCRA utilities reviewed this area (Reference 3-3) and noted the following:

- There is a stark contrast in key factors affecting operating cost and business risk between current nuclear plants and an alternative generation option, a current coal plant.

- For any future nuclear option to succeed, it must address this imbalance.

- Justification of the continued development of the MHTGR as a near term option is highly dependent on its ability to offer distinctly different characteristics in dealing with this concern, relative to other near term nuclear options.

The Working Group concluded that substantial reductions in O\&M costs and business risks relative to current nuclear plant operating experience is a clear prerequisite to further use of nuclear power.

- Plant Availability/Capacity Factor - The aggregate performance of current nuclear plants has resulted in capacity factors in the mid $60 \mathrm{~s}$ in comparison to original expectations in the range of 808 . While major recent efforts to improve capacity factor have resulted in a generally increasing trend, current performance remains far below expectations. Much of the capacity factor loss has been due to extended shutdowns at indivioual plants, with sometimes devastating impact on plant owners.

In summary, current nuclear plants have experienced a number of problems including initial capital cost growth, operation and maintenance 
cost growth, and uncertain plant performance that have translated into major risks for plant owners. Considerable gains in addressing the underlying causes of these problems may be expected from regulatory reform and plant standardization. However, it is unlikely that institutional changes alone will be sufficient. Significant changes in future plant features and operational characteristics are likely to be necessary to adequately address the costs and business risks of nuclear plant ownership. 
DOE-HTGR - 88537

SECTION 4

MHTGR DISTINCT FEATURES AND DESIGN ATTRIBUTES

\begin{abstract}
Many of the issues discussed in Section 3 that present potential barriers to additional deployment of nuclear plants are driven by regulatory requirements derived from public health and safety considerations. The MHTGR has been designed to provide protection of the public through primary reliance on fundamental response characteristics under accident conditions. This provides a basis for substantially simplifying the regulatory requirements and the design. The unique characteristics of the MHTGR in this regard result from a combination of diverse HTGR technology characteristics and passive design features as discussed below.
\end{abstract}

\title{
4.1 CHARACTERISTICS ARISING FROM DIVERSE TECHNOLOGY
}

The following diverse characteristics of HTGR technology support the MHTGR approach to safety:

- Coated Particle Fuel - The use of coated fuel particles has been an integral element of HTGR technology worldwide for the past three decades. Experience has shown coated particle fuel to provide robust and effective containment of fission products over a wide range of conditions.

- High Heat Capacity - The high heat capacity of graphite in concert with the relatively lower power density of HTGR cores results in a very slow response to imbalances in heat generation and removal during accident conditions. This characteristic is illustrated in Figure 4-1, which compares the arsunt of energy absorbed by the core during an increase 
FIGURE 4-1 CORE HEAT CAPACITY COMPARISON

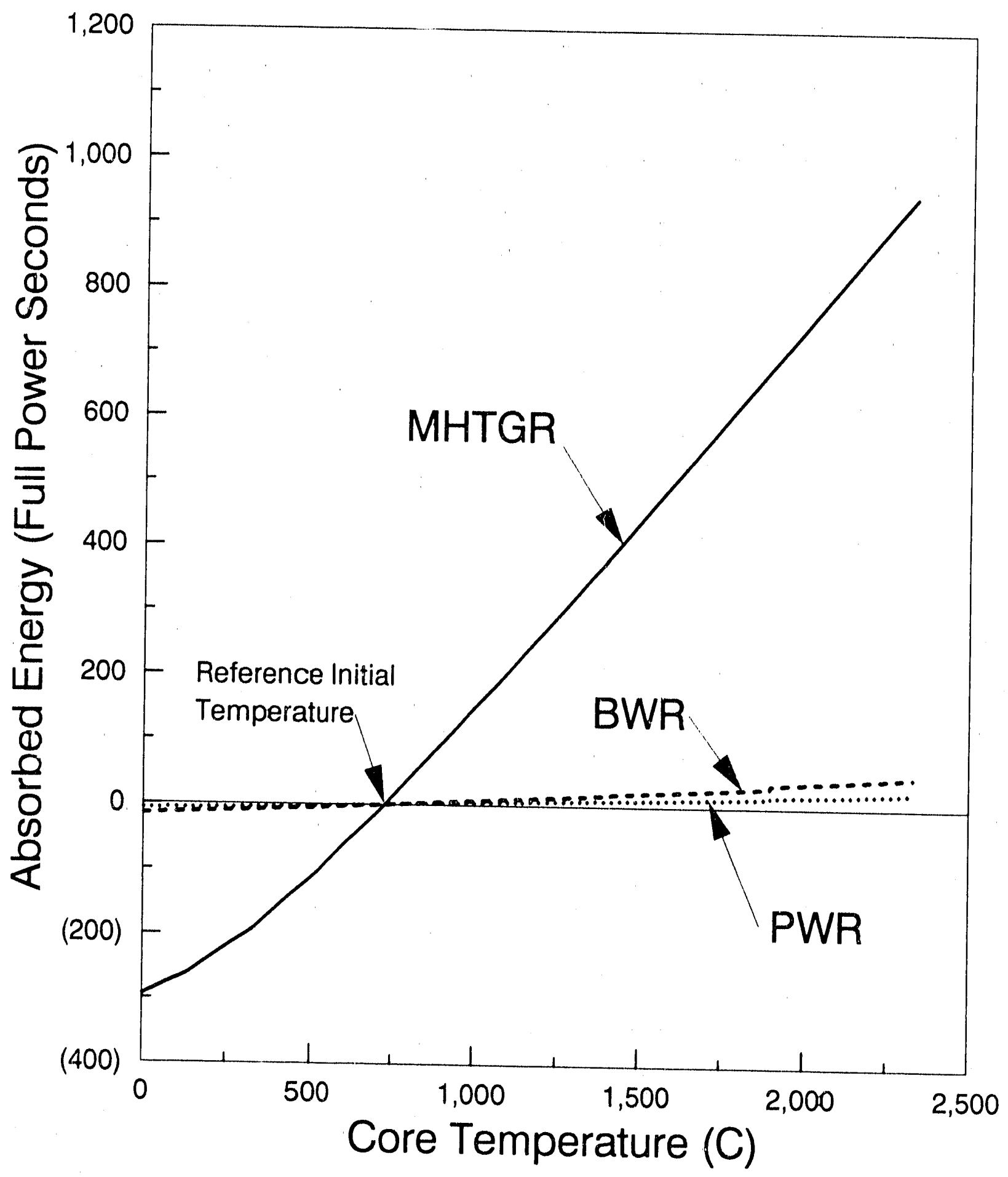

Energy Absorbed (Released) By Isothermal Heatup (Cooldown) of Core 
in temperature relative to a reference temperature for the MHTGR and current LWRs. The reference temperature is a representative nominal value for average fuel temperature at full power for both the MHTGR and LWRs. Mismatches in heat generation and removal under accident conditions are mitigated by the ability to absorb energy as core temperatures increase or decrease relative to the initial temperatures. Normalizing the core heat capacity by dividing by rated thermal power, resulting in units of full power seconds, allows a direct comparison among different systems. The large thermal capacitance of the MHTGR core is a primary factor in the unique ability of the MHTGR to withstand an indefinite loss of coolant during power operation.

- High Temperature Capability - The graphite structural elements of the core maintain strength (strength actually increasing at elevated temperature) to temperatures far in excess of conceivable accident conditions. This property provides assurance that the core remains in a well characterized geometry. Low probability accident analysis is greatly simplified and uncertainties reduced by the elimination of considerations of redistribution of core materials.

- Single Phase Coolant - Use of the noble gas helium as a coolant eliminates the possibility of a change of phase of the coolant (i.e., liquid to vapor) under accident conditions. Thus, complex semi-empirical relationships for flow and heat transfer characteristics as a function of geometry, boiling regime, etc. are avoided. Accident analysis is greatly simplified and uncertainties reduced by the elimination of consideration of two-phase flow and heat transfer.

The combined characteristics of very high integrity fuel, high temperature structural capability, and slow thermal response provide the foundation for a unique approach to retention of radionuclides. The essential elements of this approach are discussed in the following section. 


\subsection{PASSIVE FEATURES TO LIMIT ACCIDENT RESPONSE}

The following design features were established for the MHTGR, in conjunction with the characteristics discussed in the previous section, to provide fundamental response characteristics under accident conditions. These features perform their safety functions by remaining in their normal state. No sensors, actuation logic, or actuating devices are required to respond to accident conditions.

- Negative Reactivity Coefficient - The core configuration and fuel characteristics are specifically designed to provide a strong negative temperature coefficient of reactivity over the full ringe of operating conditions. As a result, increases in temperature resulting from imbalances in energy generation and removal automatically act to decrease reactor power. This characteristic places an inherent limit on temperatures that can be achieved while the core is critical.

- Meximum Power Level/Annular Core Configuration/Uninsulated Steel Reactor Vesse1 - These design features are specified to limit the amount of decay heat and allow removal of decay heat by thermal radiation from the reactor vessel while maintaining coated particle fuel temperatures within allowable limits. The power level limit results in a low power density, a key factor in the heat capacity characteristic discussed earlier. These characteristics, in concert with the high heat capacity. place an inherent limit on the fuel and structural material temperatures which can be reached due to post-shutdown decay heat under accident conditions.

- Reactor Cavity Cooling System - The Reactor Cavity Cooling System (RCCS) removes heat from the reactor cavity by natural circulation of outside air through ductwork and heat exchangers located within the reactor cavity. The RCCS cools the reactor cavity concrete under normal operating conditions and in conjunction with the features discussed above limits the reactor internals and reactor vessel to acceptable temperatures under accident conditions. 
- Reactor Building - The massive partially below grade reactor buildiag provides effective protection against external events, and a tortuous path to the environment for the small amounts of radionuclides that may be released from the reactor under accident conditions.

A limited number of additional features are specified in the current design which require sensors, actuation logic and devices, and are required to respond under accident conditions, as discussed in the following section.

\subsection{ADDITIONAL SAFETY FEATURES}

In addition to the above characteristics and features, the MHTGR design incorporaces a limited number of features, as discussed below, which require sensors, actuation logic, and actuation devices, and are designed to respond under accident conditions to limit offsite consequences.

- Control Rods - Control rods are activated by redundant sensors and protection logic to terminate the fission process under accident conditions. In the short run (minutes to hours) the control rods act to limit the conditions experienced by reactor module components as an investment protection function. In the longer run (days), they provide shutdown capability to prevent extended exposure of the fuel to excessive temperatures following decay of the core xenon inventory.

- Reserve Shutdown System - The reserve shutdown system is also activated by redundant sensors and protection logic to provide diverse capability to terminate the fission process as a backup to the control rods, as well as the capability to maintain cold shutdown under all conditions.

- Main Loop Shutdown - Main loop shutdown involves a trip of the main circulator and closure of isolation valves on the main steam and feedwater lines. In the short run (seconds to hours), main loop shutdown acts to limit the conditions experienced by reactor module components as an investment protection function. In the longer run (days), it was intended to provide shutdown capability by limiting the 
potential for dupletion of control materials through reaction of boron carbide with high temperature steam. A subsequent change to coated boron carbide control materiels may eliminate this safety function.

The MHTGR has $b$-on designed to minimize the need for systems that are required to respond to accident conditions. Further, it has been designed to limit the extent and type of support systems required. For example, the electrical load requirements of the above systems are low enough that they can be met with station batteries. Further, the required resporse times are long, typically hours to days. This eliminates the complexity and potential reliability problems associated with quick starting emergency diesel generators. The intended result is a substantial simpiffication of the design, construction, operation, maintenance, and survellance requirements for protection of public health and safety, relative to current generation nuclear plants. This subject is addressed further in a comparison of Technical Specification requirements in Appendix A.

\subsection{SAFETY AND LICENSING PERFORMANCE CHARACTERISTICS}

Immediately after selection of the reference MHTGR design, extensive safety analyses of the concept were performed and documented in the Preliminary Safety Information Document (PSID), Reference 4-1, and the Probabilistic Risk Assessment (PRA) report, Reference 4-2. These documents and supporting information were submitted to the Nuclear Regulatory Commission in the fall of 1986, and reviewed extensively during fiscal year 1987. The results and conclusions of these and subsequent interactions between the MHTGR Program and the NRC were documented by the NRC in a draft Safety Evaluation Report (Reference 4-3). A broad overview of the MHTGR preapplication 1icensing review process was documented by GCRA in Reference $4-4$.

In addition to NRC staff resources applied to the review, the NRC contracted with Brookhaven and Oak Ridge National Laboratories to conduct independent analyses and sensitivity studies of the more critical events. The NRC contractor analysis methods addressed the nuclear and 
thermal/hydraulic response, and focused on limiting events considered most likely to produce offsite doses. These included large, rapid reactivity insertions; extended total fallure of the passive Reactor Cavity Cooling System; vessel structural failure with extended air flow through the core; and steam generator tube fallures.

Example results from the NRC contractor analyses are shown in Figures 4-2 and 4-3, taken from the NRC Safety Analysis Report (Reference 4-3). Both analyses assume a loss of coolant coincident with loss of both the normal and backup heat removal systems. Figure 4-2 is a "best estimate" case, while Figure 4-3 uses conservative parameters and assumes a complete loss of the natural circulation Reactor Cavity Cooling System. In its discussion of the analysis in Reference 4-3, ORNL noted that "A complete failure of the RCCS is currently seen as a non-mechanistic failure, since no reasonable total failure mechanisms have been postulated". These results demonstrate the self-limiting nature of the MHTGR design. Sensitivity studies were also conducted to determine the relative importance of uncertainties in the analytical methods.

The analytical models used by the NRC contractors were independent of the models used by the HTGR Program, with input parameters based on submitted design information. In general, the independent analyses were in excellent agreement with the DOE contractor results, greatly enhancing confidence in the safety performance of the MHTGR. In addition, the short time scale and limited resources required to produce the independent results confirmed that the MHTGR design allows the use of relatively simple, straightforward analytical methods for safety analysis. 


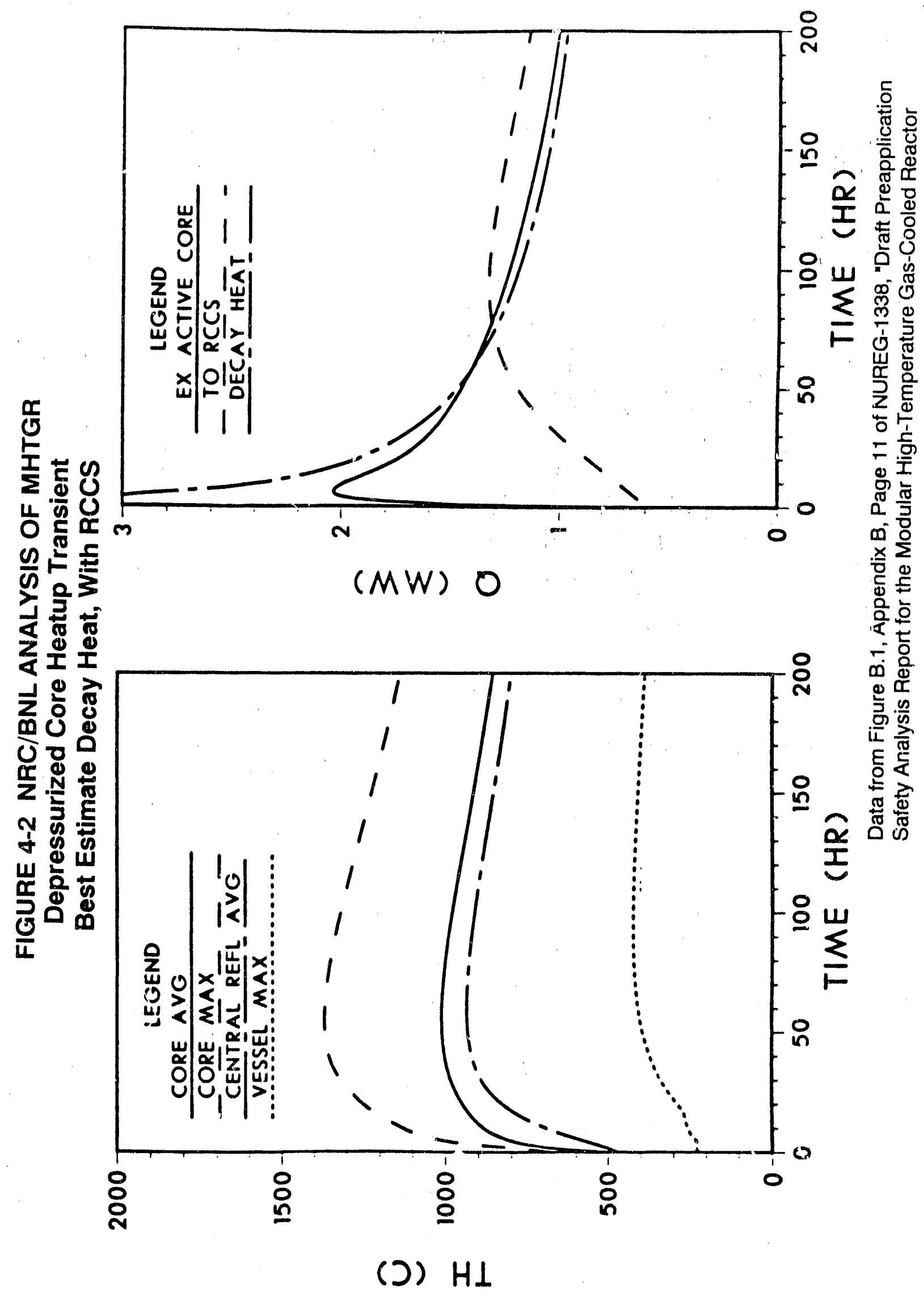


FIGURE 4-3 NRC/ORNL ANALYSIS OF MHTGR

Depressurized Core Heatup Transient

PSID Decay Heat, RCCS Failed

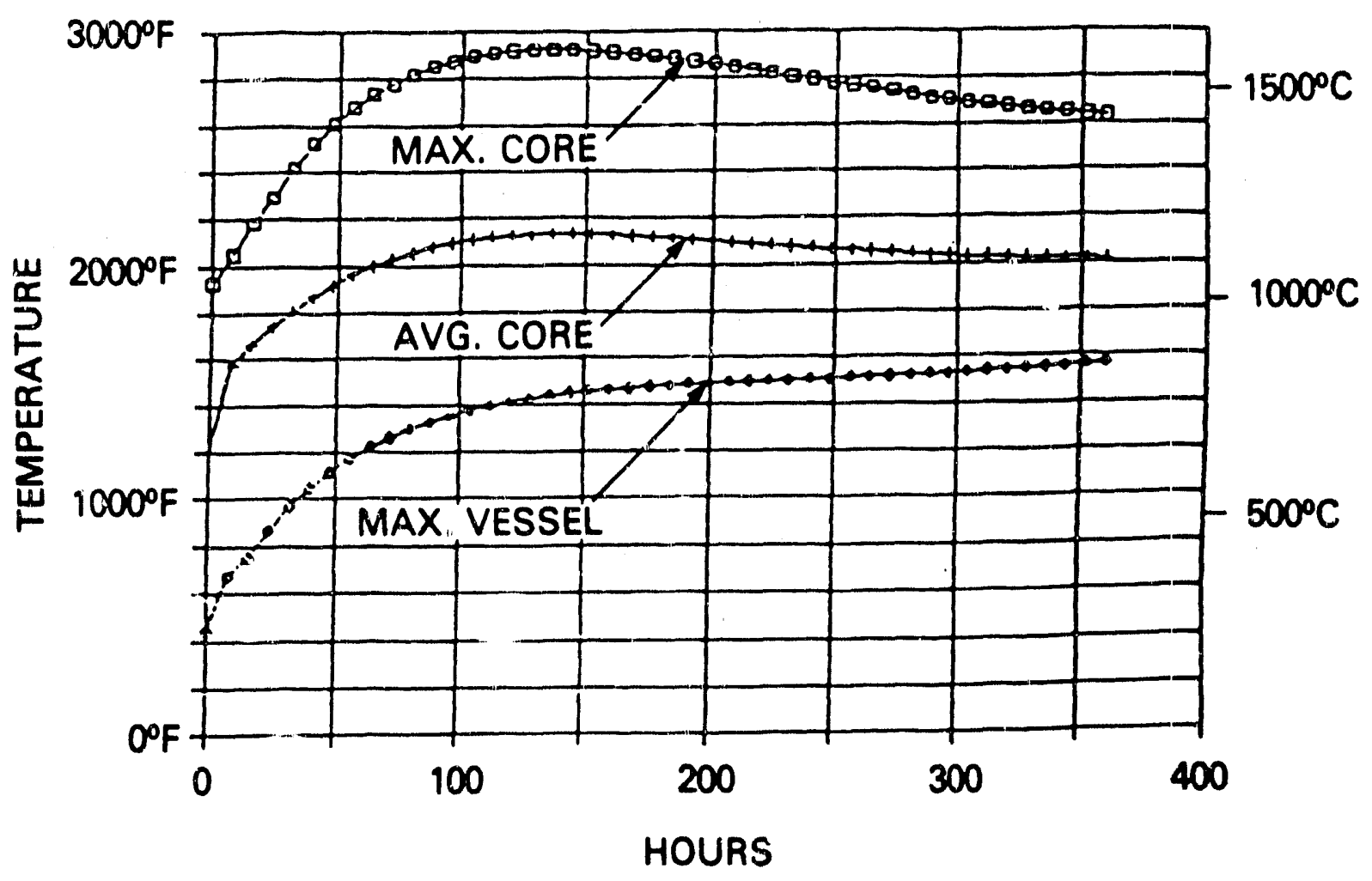

DMAX. CORE + AVG. CORE $\triangle$ MAX. VESSEL 
DOE - HTGR - 88537

SECTION 5

QUANTIFICATION OF PRODUCT DISTINCTION BENEFITS

As discussed in the previous section, the MHTGR offers distinct characteristics that differ substantially from current generation nuclear plants. However, for the MHTGR to be viable these characteristics must translate into economic benefits that offset the penalties associated with reduced unit size and the relatively higher costs of coated particle fuel. The first two subsections address the potential for simplification of regulatory requirements through a comparison of safety related equipment and Technical Specifications. The final subsection attempts to quantify economic benefits arising primarily from avoidance of costs experienced by current generation plants.

\subsection{COMPARISON OF SAFETY RELATED SYSTEMS AND STRUCTURES}

An important mearure of the extent of regulatory involvement in plant design, construction, operation and maintenance is the extent of safety related equipment. Identification of equipment as safety related places demands for quality assurance, maintenance, surveillance, security, personnel training, documentation, etc., that current experience shows can be extremely costly, as discussed briefly in Section 3.

Table 5-1 compares safety related systems and structures initially proposed by the MHTGR Program and the NRC for the MHTGR with a current generation nuclear plant. The MHTGR list includes equipment identified by the MHTGR Program and additions proposed by NRC staff as a result of the preapplication review. The current LWR plant list was developed from a Final Safety Analysis Report for an operating plant. The number of items in the list is substantially lower for the MHTGR, a clear indication of potential for simplification of regulatory requirements. Of equal or perhaps greater importance is the absense of systems imposing large electrical loads, rapid response, and precise inme sequencing from the 
TABLE 5-1

COMPARISON OF SAFETY-RELATED SYSTEMS AND STRUCTURES

$\underline{\operatorname{MHTRR}}(1),(2)$

$\underline{\operatorname{LWR}}(3)$

\section{SYSTEMS:}

- REACTOR SYSTEM

- Fue1 Elements

- Control Rods

- Control Rod Drives

- Core Support Structures

- Upper Plenum Thermal

Protection Structure

- VESSEL SYSTEM

- Reactor Vessel \& Supports

- S/G Vessel \& Supports

- Pressure Relief Valves

- Cross Duct Vessel

- Steam Generator Isolation Valves

- [Steam Generator]
- REACTOR EQUIPMENT

- Fuel Assemblies

- Control Element Assembly

- Control Element Drives

- Core Support Structures
- PRIMARY SYSTEM COMPONENTS

- Reactor Vessel \& Supports

- Steam Generators \& Supports

- Safety \& Relief Valves

- Reactor Coolant Pressure Boundary Piping

- Main Steam/Feedwater Isolation Valves

- Pressurizer \& Supports

- Reactor Coolant Pumps \& Supports

- Safety Injection \& Shutdown Cooling System

- Condensate Storage Facilities

- Auxiliary Feedwater System

- Main Steam Piping in Containment

- Containment Spray System

- Essential Spray Pond System

- Essential Cooling Water System 
TABLE 5-1

COMPARISON OF SAFETY-RELATED SYSTEMS AND STRUCTURES (cont'd)

$\underline{\operatorname{MHTGR}}(1),(2)$

- Essential Uninterruptable

Power Supply System

(120v AC)

- Essential DC Power Supply System

- Plant Protection \&

Instrumentation System

(Safety Protection Portion)

- Circulator Cooling Water System]

- [Service Water System 1

- [Helium Purification System]
$\underline{\operatorname{LWR}}$ (3)

- Electric Systems

- 4.16kV Class $1 \mathrm{E} \mathrm{AC}$

- 480V Class 1E AC

- 120V Vital AC

- Class 1E DC Equipment

- Diesel Generator \& Fuel System

- P1ant Protection System

- Reactor Protective System

- Engineered Safety Features Actuation System

- Safe Shutdown Instrunentation and Control Systems

- Essential Chilled Water System

- HVAC

- Chemical and Volume Control System

- Fuel Handling \& Storage

- Fuel Pool Cooling \& Cleanup Sys

- Nuclear Cooling Water System

- Radiation Monitoring System

- Containment Building Combustible Gas Control Systems

- Sampling System

- Gaseous Radwaste System 


\section{TABLE 5-1}

COMPARISON OF SAFETY-RELATED SYSTEMS AND STRUCTURES (cont'd)

$$
\text { MHTGR }(1),(2)
$$

LWR: $(3)$

\section{STRUCIURES:}

- Reactor Bldg

- Reactor Auxiliary Bldg

- Reactor Service B1dg
- Containment Bldg

- Auxiliary Bldg

- Control B1dg

- Fuel Bldg

- Diesel Generator Bldg

- Main Steam Support Structure

- Condensate Tank Foundation

- Essential Spray Ponds \& Intake Structure

- Refueling Water Tank Foundation

(1) - MHTGR Preliminary Safety Information Document, Table 3.2-4 (Current design results indicate several of the above items may be removed from the safety-related category)

(2) - Systems in [] Proposed by NRC in Draft SER

(3) - Current LWR Final. Safety Analysis Report 
MHTGR 1ist. This consideration is discussed further in the next subsection.

\subsection{COMPARISON OF TECHNICAL SPECIFICATIONS}

A summation of the number of safety limits and LCOs for the three plants are listed in Table 5-2. The number of safety limits are comparable for the three plants, although the PWR core safety limit has no counterpart in the MHTGR, and is considerably more complex in application than the reactor vessel presarre safety limit common to both. The PWR has the most LCOs (118) with FSV having a total of 80 . The MHTGR had the fewest unique LCOs with 34 , of which 21 are specific to individual modules and 13 are applicable to the total plant for a total of 97 . The fewer unique LCOs for the MHTGR is an asset regarding training of plant personnel in their use. Surveillance testing for module specific LCOs will have to be performed for each module, which puts a multiplier on the number of effective LCOs. The PWR LCOs require extensive time response testing related to reactor trip and engineered safety feature instrumentation. The MHTGR and FSV do not have any time response testing requirements. The conventional containment imposes more LCOs which in turn have extensive survelllance requirements for containment leakage testing and containment isolation system testing.

\subsection{QUANTIFICATION OF AVOIDED RISKS}

The complexity of factors affecting current plant experience along with the speculative nature of the degree of regulatory acceptance of the MHTGR approach precludes a rigorous quantification of avoided risks. However, the considerations summarized in Section 4 are recognized to involve substantial costs and ownership risks. This section presents an approach to quantifying these risks relative to the projected characteristics of the MHTGR in terms of the avoided busbar cost of electricity. The results are considered only crude approximations in most cases, with errors of a factor of two or more easily possible. However, the bottom line of total avoided costs of the order of 20 to $50 \mathrm{Mills} / \mathrm{kWh}$ is a significant factor in a 
Table 5-2

TECHNICAL SPECIFICATION COMPARISON SUMMARY

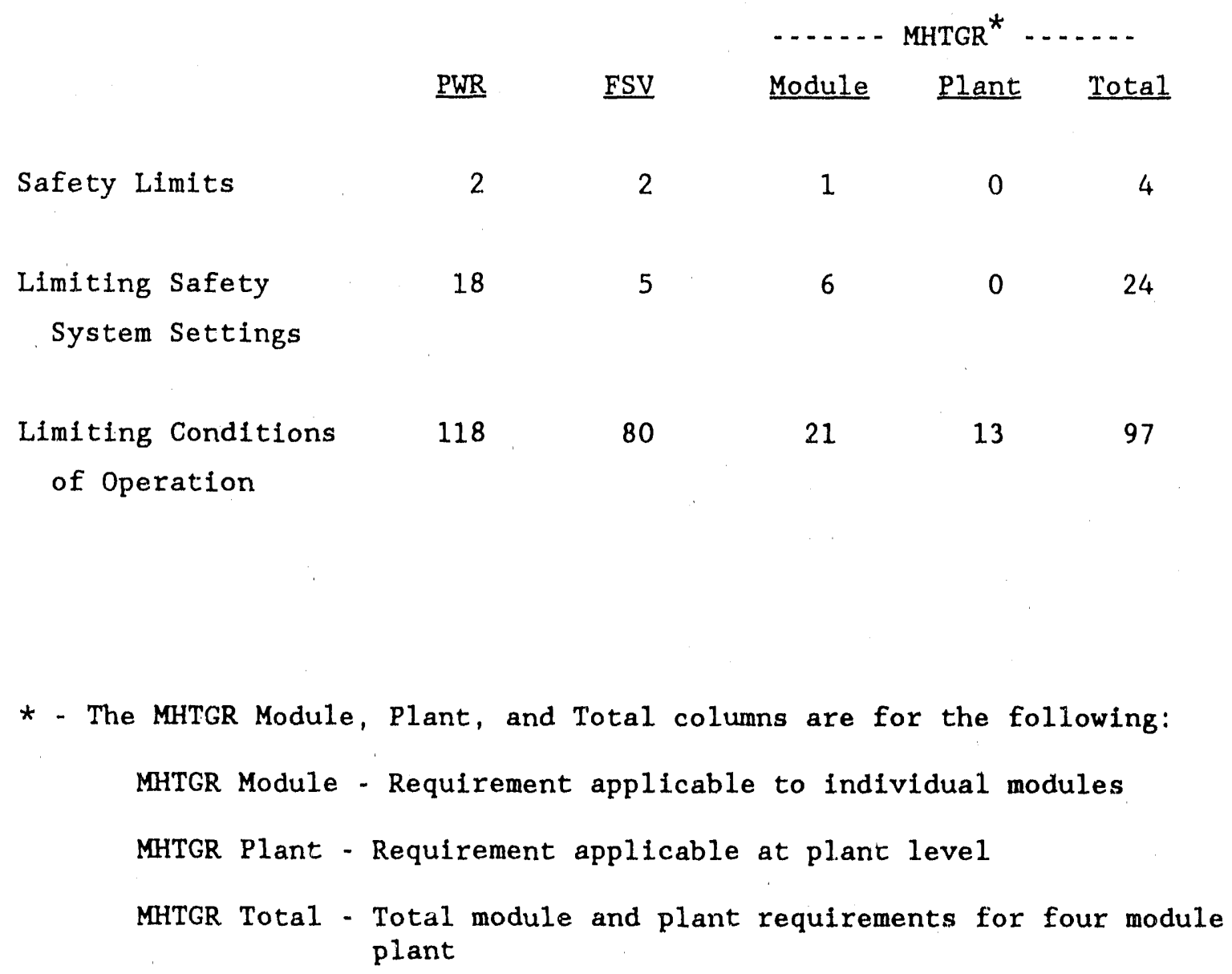


competitive economic analysis, and justificatior for continuing development of the MHTGR.

The following parameters were taken from the most recent MHTGR cost profection report (Reference 5-1) to estimate costs:

- Total Plant Capital Cost - \$1240 million (Table 4-2c)

- Busbar Cost Capital Component - 31 Mills/kWh (Table 5-5)

- Real (inflation-adjusted) cost of money - 6.05 $8 / y r$ (Table 4-3)

- Total O\&M costs - $\$ 35$ million/yr (Table 5-3)

In addition, a replacement power cost of $50 \mathrm{Mills} / \mathrm{kWh}$ was assumed. These parameters were used in the following sections to convert all estimated avoided costs to Mills/kWh.

\subsubsection{Load Matching}

The benefits of improved load matching through smaller incremental capacity additions were estimated from current plant experience summarized in section 3. As noted there, the average delay in the start of commercial operation was 55 months. A significant amount of the delay incurred resulted from intentional stretchout of construction schedules because of projections of excess capacity if the plant were completed on schedule. The per plant capital cost increase resulting from interest during construction was estimated using the following assumptions:

- Half of the 55 month average current plant startup delay is due to projections of excess capacity.

- The nominal average investment during the delay is half the total plant capital cost. 
- Operation and maintenance costs during the delay are half the costs experienced during commercial operation.

With these assumptions, the avoided costs are estimated as follows:

Capital Charge $=0.5 \mathrm{x}(\$ 1240$ million $) \times(27.5 / 12$ yrs $) \times(.06 / y r)-\$ 85$ million

O\&M Charge $-0.5 \times(\$ 35$ million $/ \mathrm{yr}) \times(27.5 / 12$ yrs $)-\$ 40$ million

Total Busbar Cost $=(\$ 85+\$ 40$ million $) \times \frac{31 \mathrm{Mills} / \mathrm{kWh}}{\$ 1240 \mathrm{million}}=3.1 \mathrm{Mills} / \mathrm{kWh}$

As a check on this approach, an entirely different approach to determining the effect of unit size and schedule on load matching was taken as documented in Appendix B. The system-wide penalty was found to be relatively insensitive to system size, making the per unit penalty roughly inversely proportional to system size. For a 5000 MWe system, a per unit penalty of about $\$ 40$ million (to be compared to capital charge element above) resulted. Since the approach taken assumed the underlying demand growth rate was equal to the growth rate used in generation planning, the approach would probably underpredict the resulting penalty. Thus it can be concluded that the capital charge identified above is reasonable within the framework of this assessment.

\subsubsection{Commercial Operation Delays}

A substantial amount of the delay in commercial operation experienced by current generation plants was incurred die to complications arising from the satisfaction of complex and evolving regulatory requirements. As noted in earlier discussions, the MHTGR design is expected to result in substantial simplifications of regulatory requirements. The benefits of reductions in commercial operation delays are estimated using the following as sumptions :

- Half of the remaining average current plant delay (27.5 months) is avoided. 
- The nominal investment during the delay is the total plant cost

- Ful1 O\&M costs are incurred during the delay

With these assumptions, the avoided costs are estimated as follows:

Capital Charge $-(\$ 1240$ million $) \times(13.75 / 12$ yrs $) \times(.06 / y r)=\$ 85$ million

O\&M Charge $=(\$ 35$ million $/ \mathrm{yr}) \times(13.75 / 12 \mathrm{yrs})=\$ 40$ milition

Total, Busbar Cost $=(\$ 85+\$ 40 \mathrm{million}) \times \frac{31 \mathrm{Mi} 1 \mathrm{~s} / \mathrm{kWh}}{\$ 1240 \mathrm{million}}=3.1 \mathrm{Mills} / \mathrm{kWh}$

\section{3 .3 Role of the Operator}

The Program's position in the PSID submittal (Reference 4-1) and review has been that the operator has no role in accident mitigation for protection of public health and safety. This position met with conditioned. acceptance by NRC staff in the draft Safety Evaluation Report (Reference 4-3). Avoided costs derived from the role of plant operators are estimated below:

Replacement Power Costs - Current exper:ience has shown instances of operators failing to pass requalification exams on response to accidents in sufficient numbers to cause plant shutdown (see Reference 5-2). For purposes of quantification of costs, assume two shutdowns per year of three months duration in a population of 100 plants. The avoided costs can be estimated as:

$\frac{(550 \mathrm{MW}) \times(\$ 50 / \mathrm{MWhr}) \times(0.25 \times 8760 \mathrm{hr})}{(0.8) \times(550 \mathrm{MW}) \times(8760 \mathrm{hr})} \times \frac{2 \mathrm{plants}}{100 \mathrm{plants}}-0.3 \mathrm{M} 111 \mathrm{~s} / \mathrm{kWh}$

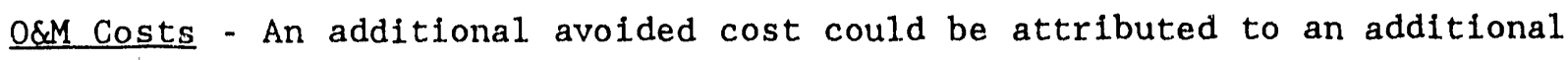
shift of operators (7) plus an additional 20 personnel in the training department. Assuming non-fuel O\&M costs are proportional to staffing level 
and ratioing from the staffing total (303), and levelized busbar costs for non-fuel O\&M (9.29 Mills $/ \mathrm{kWh}$ ) from Table $4-6$ of Reference 5-3 results in the following additional avoided costs:

$$
\frac{27 \text { personne }}{303 \text { personne1 }} \times(9.29 \mathrm{Mills} / \mathrm{kWh})=0.8 \mathrm{Mil1s} / \mathrm{kWh}
$$

Plant Abandonment - Based on current plant experience, assume one plant out of a population of 100 would be abandoned after all accident involving operator actions which exacerbated the consequences. Assuming recovery and decommissioning costs of $\$ 1$ billion, the estimated levelized cost is:

$\frac{(1 \mathrm{plant}) \times(\$ 2240 \mathrm{mi} 11 \text { ion })}{(100 \mathrm{plants}) \times(\$ 1240 \mathrm{million})} \times(31 \mathrm{Mi11 \textrm {s }} / \mathrm{kWh})-0.6 \mathrm{Mi11 \textrm {s }} / \mathrm{kWh}$

The estimated avoided cost due to eliminating the role of the operator in mitigating accidents is $1.7 \mathrm{Mills} / \mathrm{kWh}$.

\subsubsection{Emergency Planning}

A fundamental requirement of the MHTGR has been to meet regulatory criteria without credit for sheltering or evacuation of the public beyond the plant's exclusion area boundary. This issue received considerable attention during the preapplication licensing review. The NRC staff's recommendations, as documented in Reference 4-3, were generally supportive of the Program's position.

Siting Costs - Emergency planning considerations have a significant impact on siting evaluations, requiring considerable costs to develop, evaluate, and litigate meteorological and demographical considerations. Elimination of otherwise acceptable sites further increases siting costs. Assume nominal additional costs associated with these considerations of $\$ 100$ million, resulting in the following busbar costs:

$$
\frac{\$ 100 \text { million }}{\$ 1240 \text { million }} \times(31 \mathrm{Mills} / \mathrm{kWh})-2.5 \mathrm{Mills} / \mathrm{kWh}
$$


Initial Program Development Costs - Recent experience with cost of establishing an accepted emergency planning process show costs in the neighborhood of $\$ 25$ milition. Thus the contribution to busbar costs of an additional $\$ 25$ milion expenditure is estimated as follows:

$\frac{\$ 25 \mathrm{million}}{\$ 1240 \mathrm{million}} \times(31 \mathrm{Mi1ls} / \mathrm{kWh})=0.6 \mathrm{Mills} / \mathrm{kWh}$

Program Operating Costs - Assume the annualized staff for coordinating and participating in emergency drills is 10 personnel. Using the same approach as Section A.5.3.3:

$\frac{10 \text { personnel }}{303 \text { personnel }} \times(9.29 \mathrm{Mills} / \mathrm{kWh})=0.3 \mathrm{Mil1 \textrm {s }} / \mathrm{kWh}$

Plant Startup Delay - Based on recent experience, assume 5 plants out of a population of 100 would experience a startup delay of 1 year due to emergency planning. The capital charge is estimated, using the total capital cost of $\$ 1240$ million and a nominal real cost of money of $6.05 \% / y r$, as $\$ 75$ million. The $O \& M$ cost/yr is $\$ 35$ million as noted earlier. The estimated levelized cost is:

$\frac{(5 \text { plants }) \times(\$ 110 \mathrm{million})}{(100 \text { plants }) \times(\$ 1240 \mathrm{million})} \times(31 \mathrm{Mil1s} / \mathrm{kWh})-0.1 \mathrm{Mi} 11 \mathrm{~s} / \mathrm{kWh}$

Plant Abandonment - Based on recent experience, assume 1 plant out of a population of 100 would be abandoned after a two year delay. Assuming shutdown and decominsioning costs to be 208 of capital costs, the total cost is $\$ 1240+2 \times 110+0.2 \times 1240-\$ 1708$ million. The estimated levelized cost is :

$\frac{(1 \mathrm{plant}) \times(\$ 1708 \mathrm{million})}{(100 \mathrm{plants}) \times\left(\$ 1240 \mathrm{~m}^{2}: 11 \mathrm{on}\right)} \times(31 \mathrm{Mills} / \mathrm{kWh})-0.4 \mathrm{Mi11 \textrm {s }} / \mathrm{kWh}$

The total quantified costs from the above factors amount to $\underline{3.9}$ 
Mills $/ \mathrm{kWh}$. Another factor which has not been quantified is the intangible cost which may arise for the plant owner/operator from negative publicity and community relations, which may be more significant than the factors which have been quantifled.

\subsubsection{Regulatory Requirements Simplification}

As noted earlier, the response characteristics of the MHTGR offers the potential for substantial simplification of regulatory requiremerts (see discussion on page 1-1 of Reference 5-3). The discussions in sections A.5.1 and A.5.2 provide some early indications of this potential. Estimates of avoided costs relative to current generation plants are developed from the following considerations:

Replacement Power Costs - The complexities of current regulatory requirements have caused relatively frequent extended outages at current plants for a variety of reasons. The times for revising documentation, organizational development, plant modifications, etc., to meet restart requirements have been as long as several years. As a rough indication of the likelihood of this situation, the capacity factor for 1989 was less than 208 for ten plants (Reference 5-4). Not all of the problems were related to complexity of regulatory requirements, so for the purposes of this estimate, assume 5 plants in a population of 100 down for an extended outage driven by regulatory requirements at any given time. The avoided costs can be estimated as:

$$
\frac{(550 \mathrm{MW}) \times(\$ 50 / \mathrm{MWh}) \times(8760 \mathrm{hr})}{(0.8) \times(550 \mathrm{MW}) \times(8760 \mathrm{hr})} \times \frac{5 \text { plants }}{100 \text { plants }}-3.1 \mathrm{Mills} / \mathrm{kWh}
$$

OSM Costs - A review of existing plant staff sizes by the GCRA Ut1lity Working Group (see Reference 5-3), along with other current evaluations, indicate a nominal size for current plants of about 800 personnel. The difference between this number and the 303 personnel profected for the MHTGR target plant in Reference 5-3 is assumed to be the result of operational regulatory requirements simplification and standardized, 
automated operating systems, as discussed in the following section. The reduction in plant staffing requirements is assumed to be equaliy split between these two areas. Using the same approach as the previous section and excluding the 27 additional personnel assigned to the role of the operator and 10 personnel for emergency response results in the following estimate:

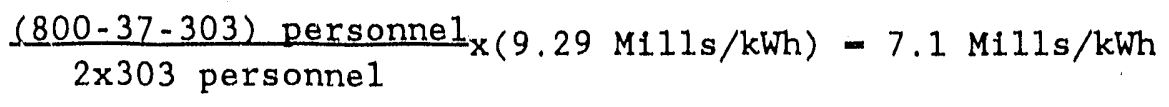

Cost of Money - If substantial differences in the risk of plant construction and operation, due to differences in complexity of regulatory requirements, are present, corresponding differences in the cost of money to finance the plant can be expected. As a first cut, a difference of 28 in interest rates and return on equity was assumed and the effect on busbar cost was calculated. Relative to the reference Target Plant cost estimate capital charge (Table 5-5 of Reference 5-1), this increased the levelized busbar cost by $5.6 \mathrm{Mill} / \mathrm{s} / \mathrm{kWh}$.

Summing up, the total avoided cost attributed to simplification of regulatory requirements is estimated to be $15.8 \mathrm{Mills} / \mathrm{kWh}$.

\subsubsection{Standardized, Automated Operating Systems}

In developing the MHTGR O\&M cost projections, a standardized, highly automated operating environment was assumed. In addition to automated plant control systems, a full range of automated operating programs were assumed, ranging from preventive maintenance to OSHA hazardous materials programs (see Table 3-2 of Reference 5-3). In addition, for the target MHTGR plint, a central operations support organization providing services to many staindard plants was assumed (Reference 5-5) defines the central operations sipport concept). As noted in the previous section, the remaining avoided cost from reductions in plant staffing relative to current generation plants was assumed to result from these considerations, resulting in the following estimate: 


\section{$\frac{(800-37-303) \text { personnel }}{2 \times 303 \text { personnel }} \times(9.29 \mathrm{Mills} / \mathrm{kWh})-7.1 \mathrm{Mills} / \mathrm{kWh}$}

As noted earlier, the results of this and previous sections are tabulated in Table 5-3.

\subsection{SUMMARY OF AVOIDED COST}

T. bottom line results of the quantification of potential avoided cost for the MHTGR relative to current plant experience developed in Section 5.3 are summarized in Table 5-3. At present, the evaluated power cost estimate for the MHTGR, which inherently incorporates the avoilded cost benefits discussed in this section (since the costs were not added in), is in the range of $50 \mathrm{Mills} / \mathrm{kWh}$ ('90\$). The avoided risks equivalent to $35 \mathrm{Mills} / \mathrm{kWh}$ would represent a very large increase in power costs if the expected benefits of the MHTGR approach did not materialize. On the other hand, it is the potential for overcoming economies of scale penalties relative to larger plants by providing these benefits which makes the MHTGR a viable future option. In considering these results, it must be recognized that the costs were developed in a subjective and very approximate manner in the context of nuclear experience to date. However, whether the total is 20 , 35 , or $50 \mathrm{mills} / \mathrm{kWh}$, the importance of effectively addressirg the issues is clear. 
TABLE 5-3

ESTIMATED AVOIDED COST*

\section{Topical Area}

1. Load Matching

2. Commercial Operation Delays

3. Role of the Operator

- Replacement Power Cost

- O\&M Costs

- Plant Abandonment

4. Emergency Planning

- Siting Costs

- Initial Program Development

- Program Operating Cost

- Plant Startup Delay

- Plant Abandonment
Subtotal

$(\mathrm{M} / \mathrm{kWh})$
Total

$(M / k W h)$

3.1

3.1

1.7

0.3

0.8

0.6

5. Regulatory Requirements Simplification

- Replacement Power Cost

3.1

- O\&M Cost

7.1

- Cost of Money

2.5

0.6

0.3

0.1

0.4

3.9

6. Standard, Automated Operating Systems

7.1

Total Estimated Avoided Cost

${ }^{\star}$ Expressed as avoided busbar cost of electricity. 


\section{SECTION 6}

\section{REFERENCES}

1-1 California Energy Commission, Energy Development Report, Committee Draft, Report numbered p500-900-007, June, 1990.

1-2 Nuclear Power in an Age of Uncertainty, Congress of the United States, Office of Technology Assessment, February 1984

3-1 "World List of Nuclear Power Plants", Nuclear News, August, 1987.

3-2 "Outlook on Personnel Costs", Nucleonics Week, June 28, 1990.

3-3 "Summary of November 29, 1989 Joint Working Group/MHTGR Program Meeting on Operational Licensing Requirements", GCRA/UTIL (0531), December 13, 1989.

4-1 "Preliminary Safety Information Document for the Standard MHTGR", HTGR-86-024, Volumes 1-5.

4-2 "Probabilistic Risk Assessment for the Modular High Temperature Gas-Cooled Reactor", DOE-HTGR-86011.

4-3 "Draft Preapplication Safety Evaluation Report for the Modular High-Temperature Gas-Cooled Reactor", NUREG-1338, March, 1989.

4-4 "MHTGR Licensing Review Summary and Status", GCRA 89-003, June, 1989.

5-1 Gas-Cooled Reactor Associates, Modular HIgh Temperature Gas-Cooled Reactor Plant Capital and Busbar Generation Cost Estimates, DOE-HTGR-87-086, May, 1990.

5-2 "CP\&L Shuts Down Brunswick Units After Operators Fail NRC Exams", Nucleonics Week, May 24, 1990, Page 2.

5-3 Gas-Cooled Reactor Associates, Utility Projections of Operation and Maintenance Costs for Modular HTGR Plants, GCRA 90-005, March, 1990.

5-4 "Nuclear Electricity Generation for December, 1989", Nucleonics Week, February 8, 1990, Page 19-20.

5-5 Development of a Central Operation Support Organization for the MHTGR, GCRA 90-004, April, 1990. 
DOE - HTGR - 88537

APPENDIX A

TECHNICAL SPECIFICATION COMPARISON 
DOE-HTGR - 88537

This appendix presents the results of a comparison of Technical Specifications conducted by General Atomics for a current generation LWR, Fort St. Vrain, and an initial projection of Technical Specification requirements for the MHTGR. Some imbalances exist in the comparison in that the LWR and Fort St. Vrain cases are based on Technical Specifications reviewed in considerable depth by the NRC, while the MHTGR Program Technical specifications are based on judgement, and have not been rigorously developed or reviewed by the NRC. Nonetheless, a solid technical basis for simplification of MHTGR Technical Specifications is expected based on the characteristics discussed in section 4.

For the purposes of this Study, non-plant-specific Standard Technical Specifications for a PWR were used in the evaluation. Upgraded but not implemented technical specifications which follow the format for LWR Standard Technical Specifications were used for FSV. The FSV upgraded Technical Specifications had been reviewed by the Nuclear Regulatory Commission (NRC). The MHTGR Technical Specification requirements address those structures, systems, and components identified to be safety-related during the Preliminary Safety Information Document (PSID) NRC review plus other items which are generic to Technical Specifications. It was assumed that if the Standard Technical Specifications format had two limiting conditions of operation (LCO) for the same parameter with one covering power operation and the second shutdown, then the MHTGR Technical Specification would also have two LCOs for the same parameter when applicable to the MHTGR. The separate LCOs for operating and shutdown accommodate different requirements and different action statements when the requirements are not satisfied.

\section{A. 1 SAFETY LIMITS AND LIMITING SAFETY SYSTEM SETTINGS}

Both the PWR and FSV have a safety limit on the reactor core. The PWR has requirements on primary coolant pressure, primary coolant average temperature, and reactor power to protect the fuel cladding by restricting fuel operation to within the nucleate bolling regime. FSV has a limitation on time at power-to-flow ratios above one. This limits fuel kernel 
migration (amoeba affect) within the fuel particle. Fuel kernel migration is now known to not be a significant contributor to fuel particle failure. A core safety limit has not been identified for the MHTGR.

Both the PWR and FSV have a safety limit on reactor vessel pressure. For the PWR it is the maximum transient pressure (1108 of design pressure). For FSV it is 1208 of peak operating pressure. The MHTGR would have a comparable safety limit on the reactor vessel pressure (1108 of design pressure).

The PWR, FSV, and MHTGR will all have limiting safety settings for reactor trip system instrumentation setpoints. The PWR Technical Specifications list setpoints for 18 parameters. FSV Technical Specifications list setpoints for five parameters. The MHTGR monitors six process parameters which initiate scram for which setpoints would be listed.

\section{A. 2 LIMITING CONDITIONS OF OPERATION}

Limiting conditions of operation for the PWR, FSV and MHTGR are summarized in Table A-1. Comparisons are as follows:

- Reactivity Control Systems: The PWR has five LCOs on boration control and six LCOs (three each for operating and three each for shutdown) on boration systems. None of these have any counterpart for FSV oi the MHT'GR.

The PWR has seven LCOs on movable control assemblies with two LCOs addressing the same parameter for operating and shutdown conditions. FSV has ten LCOS in this same category with six of the LCOs addressing three parameters in both the operating and shutdown mode. The MHTGR would have nine LCOs with six addressing the three parameters for the operating and shutdown modes. The LCOs on moveable control assemblies for the three plants are comparable. 


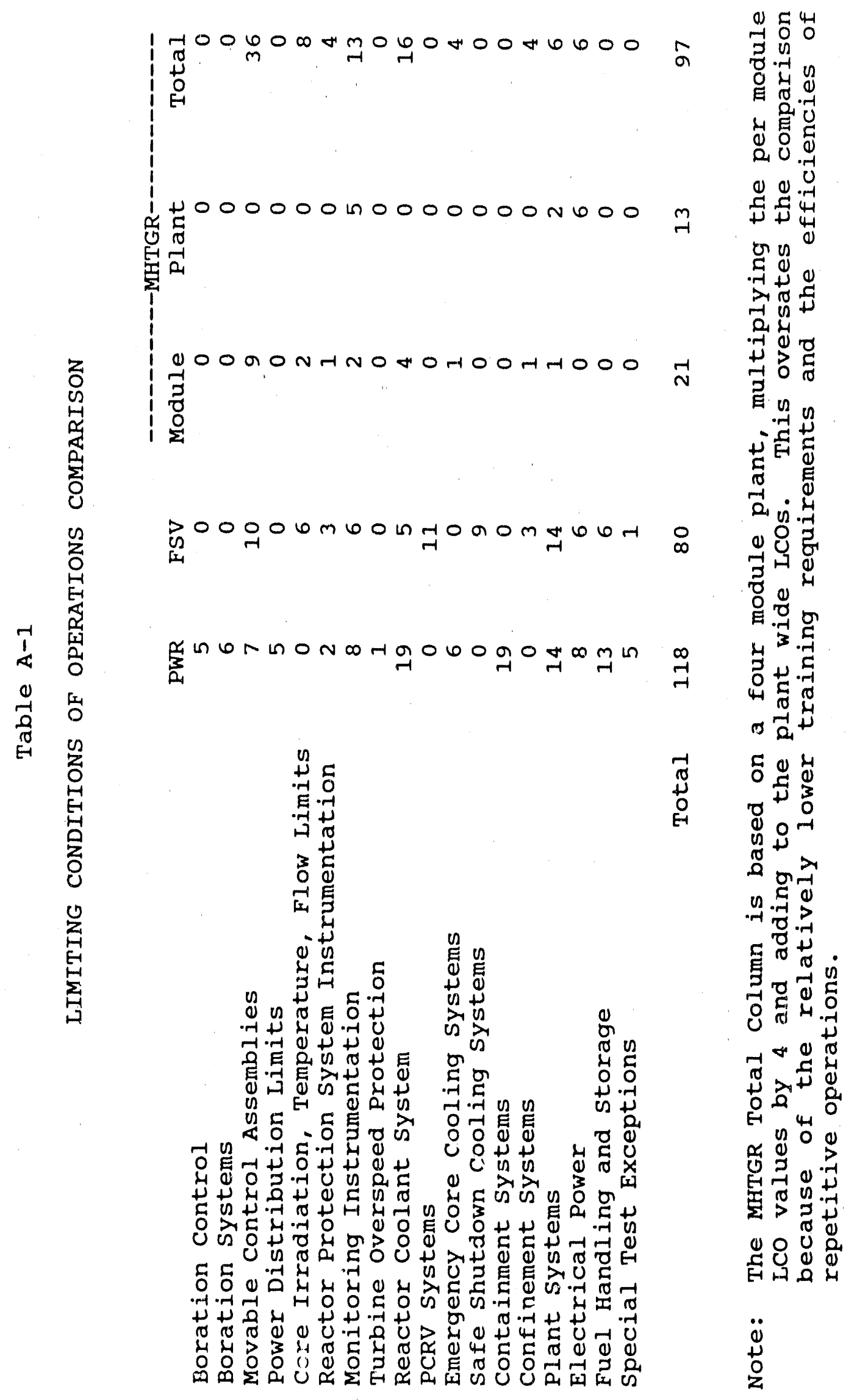


- Core Irradiation and Flow Limits: The PWR counterpart in this category would be "power distribution limits" for which there are five LCOs. FSV has six LCOs in this category. The MHTGR would have two LCOs. Core irradiation would place a limit on fuel burnup. The power-to-flow requirement would protect the fuel from sustained high temperatures. FSV Technical Specifications include these same two requirements plus minimum helium flow requirements for low power operation.

- Reactor Protection System Instrumentation: The PWR has 2 LCOs addressing requirements for reactor protection instrumentation (including the engineered safety feature actuation system instrumentation). FSV has 3 , and the MHTGR has 1 per module. Specific instrumentation issociated with the reactor protection system are discussed below.

The PWR would include both the reactor trip and the engineered safety feature actuation system instrumentation. The 18 process parameters that can cause reactor trip comprise a total of 60 instrument channels. Ten of the 18 process parameters have time response requirements specifled which must be verifled by surveillance testing. Engineered safety feature instrumentation monitor 11 process parameters and comprise a total of 67 instrument channels. All of the engineered safety feature activation instrumencation have specified time response requirements requiring verification by surveillance testing.

FSV, in addition to reactor trip instrumentation, also has loop trip and circulator trip instrumentation. The latter protect equipment used for safe shutdown cooling. The reactor trip, loop trip, and circulator trip instrumentation comprise a total of 141 instrument channels. There are no time response requirements specified for FSV.

The MHTGR reactor protection system include both rector trip and heat transport system isolation. The reactor trip system monitors six process parameters and the heat transport system isolation monttors two process parameters. These comprise a total of 32 instrument channels 
DOE - HTGR - 88537

per module for a total of 128 instrument channels for a four module plant. The MHTGR, like FSV, does not have any time response requirements.

- Monitoring Instrumentation: The PWR identifies 8 LCOs for monitoring instrumentation, and FSV Identifies 6. Monitoring instrumentation requirements for the MHTGR are as listed in Table A-1, and are comparable to the PWR and FSV, with two LCOs per module and 5 plant wide for a total of 13 for a four module plant.

- Turbine Overspeed Protection: The PWR has 1 LCO on turbine overspeed protection. FSV does not have an LCO on turbine overspeed protection, nor would the MHTGR.

- Reactor Coolant System: The PWR has 19 LCOs addressing requirements for the reactor coolant system. FSV has five LCOs on the reactor coolant system. In addition, FSV has 11 LCOs on the prestressed concrete reactor vessel (PCRV) support systems. These PCRV support systems are an addition to the reactor coolant system.

The MHTGR has four LCOs as lisced in Table A-1 which are generally comparable to the five LCOs on the reactor coolant system for FSV.

- Passive Reactor Coolant System: The reactor cavity cooling system (RCCS) is unique to the MHTGR for which there would be one LCO. The counterpart for the PWR would be the emergency core cooling system for which there are six LCOs. The counterpart for the FSV would be the safie shitdown cooling systems for which there are nine LCCs.

- Confinement Systems: The PWR counterpart is the containment systems which have $19 \mathrm{LCOs}$. The surveillance testing associated with these LCOs are significant. Three overall integrated leakage tests over a ten year interval are specified. Each containment isolation valve must be demonstrated operable every refueling. A sample of four PWR plants indicated the number of isolation ralves varied between 31 and 64 per unit. 
DOE - HTGR - 88537

FSV would have three LCOs which address wilding integrity, building exhaust system, and building over-pressure protection system.

The MHTGR has one LCO addressing reactor building integrity to ensure that the RCCS is not impaired by fallure of the reactor building.

Plant Systems: Both the PWR and FSV have 14 LCOs under this genera1 heading. FSV includes safe shutdown cooling support systems in this category.

The MHTGR has three LCOs addressing main steam isolation valves, secondary coolant activity, and area temperature monitoring.

- Electrical Power Systems: The PWR, FSV, and MHTGR have LCOs addressing AC sources, DC sources, and onsite power distribution systems. Separate LCOs are written for operating and shutdown making a total of six LCOs. The PWR LCO on AC sources addresses 4160-V switchgear and the associated diesel generators. The FSV LCO on AC sources addresses the $480-\mathrm{V}$ switchgear and the associated emergency diesel generators. The MHTGR LCO on AC sources would only address the safety-related $120-\mathrm{V}$ single phase, $60 \mathrm{~Hz}$ uninterruptable power and associated rectifiers/inverters. The standby gas-turbine generators are not safety-related and would not be included in the MHTGR LCO on AC sources.

The PWR LCO on DC sources addresses 250/125-V battery bank requirements. FSV and the MHTGR LCOs on DC power would address the plants $125-\mathrm{V}$ batteries. FSV and MHTGR do not have two divisions of DC power.

The PWR LCO on onsite power distribution address those buses which are safety-related and include $4160-$ and $480-\mathrm{V}$ emergency buses, 120-V AC vital buses, 250/125-V DC buses, and assoclated batteries. The FSV LCO a).so address the buses which are safety-related and include the $480 \mathrm{~V}$ $A C$ buses energized from the associated $4160-V$ AC buses, $120-V$ AC 
DOE - HTGR - 88537

noninterruptable buses, and the $125-\mathrm{V}$ DC buses and its associated batteries. The MHTGR would also address the buses which are safety-related and would include the essential $120-\mathrm{V}$ AC buses and the essential 125-V DC buses and its associated batteries.

The PWR also has two LCOs on electrical equipment protection devices. FSV does not have any LCOs for this category nor have any been identified for the MHTGR.

- Fuel Handling and Storage Systems: The PWR has 13 LCOs and FSV has six LCOs covering fuel handling and storage systems. For the MHTGR, fuel handling and storage are not safety-related and no LCOs have been identified for these operations.

- Special Test Exceptions: The PWR has five LCOs and FSV has one LCO on special test exceptions. None have been identified to date for the MHTGR but it is possible that some will be identified later.

\section{A. 3 SUMMARY COMPARISON OF TECHNICAL SPECIFICATIONS}

A summation of the number of safely limits and LCOs for the three plants are listed in Table 5-2. The number of safety limits are comparable for the three plants, although the PWR core safety limit has no counterpart in the MHTGR, and is considerably more complex in application than the reactor vessel pressure safety limit common to both. The PWR has the most LCOs (118) with FSV having a total of 80 . The MHTGR had the fewest unique LCOs with 34 , of which 21 are specific to individual modules and 13 are applicable to the total plant for a total of 97 . The fewer unique LCOs for the MHTGR is an asset regarding training of plant personnel in their use. Surveillance testing for module specific LCOs will have to be performed for each module, which puts a nultiplier on the number of effective LCOs. The PWR LCOs require extensive time response testing related to reactor trip and engineered safety feature instrumentation. The MHTGR and FSV do not have any time response testing requirements. The conventional containment imposes more LCOs which in turn have extensive surveillance requirements for containment leakage testing and containment isolation valve testing. 
APPENDIX B

UNIT SIZE AND CONSTRUCTION SCHEDULE EFFECT ON UTILITY LOAD MATCHING 
This appendix documents an estimate of the quantitative benefits of improved ability to match generating capacity to system load resulting from smaller units with shorter construction schedules. The relative benefits are estimated for system sizes of $2,500,5,000$, and 10,000 MWe initial total installed capacity.

The following unit sizes and completion schedules were compared:

1. 140 MWe, 3 Year Schedule - This is intended to represent incremental MHTGR module additions at existing sites.

2. 560 MWe, 5 Year Schedule - This is intended to represent installation of four module plants as a unit.

3. 1000 MWe, 7 Year Schedule - This is intended to approximate the average size and schedule duration of the population of current nuclear plants.

A net penalty was determined as the difference between either 2 or 3 and a reference represented by 1 .

The ability to match generating capacity to demand is assessed for a 30 year period under the following conditions:

1. Random year-to-year varlations in load growth.

2. Uniformly distributed annual load growth in range -28 to +78 (average annual growth 2.58 ).

3. New capacity ordering assuming a 2.58 annual growth rate and projecting a minimum margin of 17.58 forward the duration of the assumed new plant completion schedule (i.e., targeting the mid-point of a 10 to 258 capacity margin range). 
The cost penalty for each case was estimated assuming a penalty for capacity margin (total installed capacity - load) less than 108 or more than 258 of load in a given year. The average penalty for each case was determined by summing up the annual values and dividing by the number of years (30). The cost was then estimated assuming $\$ 1500 / \mathrm{kw}$ (same cost for undercapacity and overcapacity) for the average amount the capacity margin was outside the 10 to 258 range during the 30 year period. The average penalty for each set of six cases was then determined. A total of 90 cases were run for each system size with results illustrated in Tables $B-1$ and B-2, and Figures B-1 through. B-4.

Table B-1 summarizes typical results for the following sets of cases:

1. 2,500 MWe System, 140 MW unit size and 3 year completion schedule versus $1000 \mathrm{MW}$ unit size and 7 year completion schedule.

2. 2,500 MWe System, $140 \mathrm{MW}$ unit size and 3 year completion schedule versus $560 \mathrm{MW}$ unit size and 5 year complation schedule.

3. 10,000 MWe System, 140 MW unit size and 3 year completion schedule versus $1000 \mathrm{MW}$ unit size and 7 year completion schedule.

4. 10,000 MWe System, 140 MW unit size and 3 year completion schedule versus $560 \mathrm{MW}$ unit size and 5 year completion schedule.

Figures B-1 through B-4 show the time dependent variation in load and total capact.ty for the same four sets of cases. The target range for capacity margin of 10 to 258 is also shown in solid lines. Penalties are assessed when the total capacity is outside the allowed range as discussed earlier to arrive at an estimated cost.

The random load growth profections introduce large case to case variations in penalties, as illustrated in Table B-1. To gain more confidence in the results, a large number of cases (90 cases for each combination of system and unit size, for a total of 540 cases) were run. 
DOE-HTGR- 88537

The overall results, given in Table B-2, show a clear effect of unit size and schedule, but relatively little effect of system size on the penalty. The result (relative to the deployment of 140 MWe units on a 3 year schedule) is a net system-wide penalty of about $\$ 100$ Million for the 560 MWe unit with a 5 year schedule, and about $\$ 400$ Million for the 1000 MWe unit with a 7 year schedule.

The approach taken here is greatly simplified relative to the actual generation planning process, which deals with $a$ mix of unit sizes and schedules as well as base 1oad, intermediate and peaking capacity, and the interchange of bulk power with other utilities. Also, demand growth is a combination of deterministically predictable and stochastic factors, with an underlying growth rate that may vary substantially over a 30 year period. Thus the results must be taken as approximate quantifications of the load matching penalties for larger units with longer schedules.

On the other hand, the approach does allow separation of unit size and schedule effects while considering the statistical nature of the generation planning process. The fact that the ordering algorithm used is inherently consistent with the underlying average load growth may cause the approach to underpredict load matching penalties. Other factors not considered in the analysis, such as the ability to stretch out schedules (although at significant c.osts) may tend to offset this effect. It should also be noted that while the load matching penalty was found to be relatively independent of system size, converting the penalty to a per plant basis or a percentage of system investment would result in a penalty that is inversely proportional to system size. For example, the per unit penalty for a 1000 MWe unit size on a 5000 MWe system would be estimated as follows:

From Table B-2, the system-wide penalty is $\$ 330$ million. During the 30 year period (consistent with economic lifetime) of the evaluation, several plants would be orc red. In fact, the system size would approximately double. Thus, to $a^{\prime}$ 'cate this penalty (actually an avoided cost benefit) on a per plant basis for a MHTGR plant size of 560 MWe capable of being deployed in 140 MWe increments or a 5000 MWe system: 


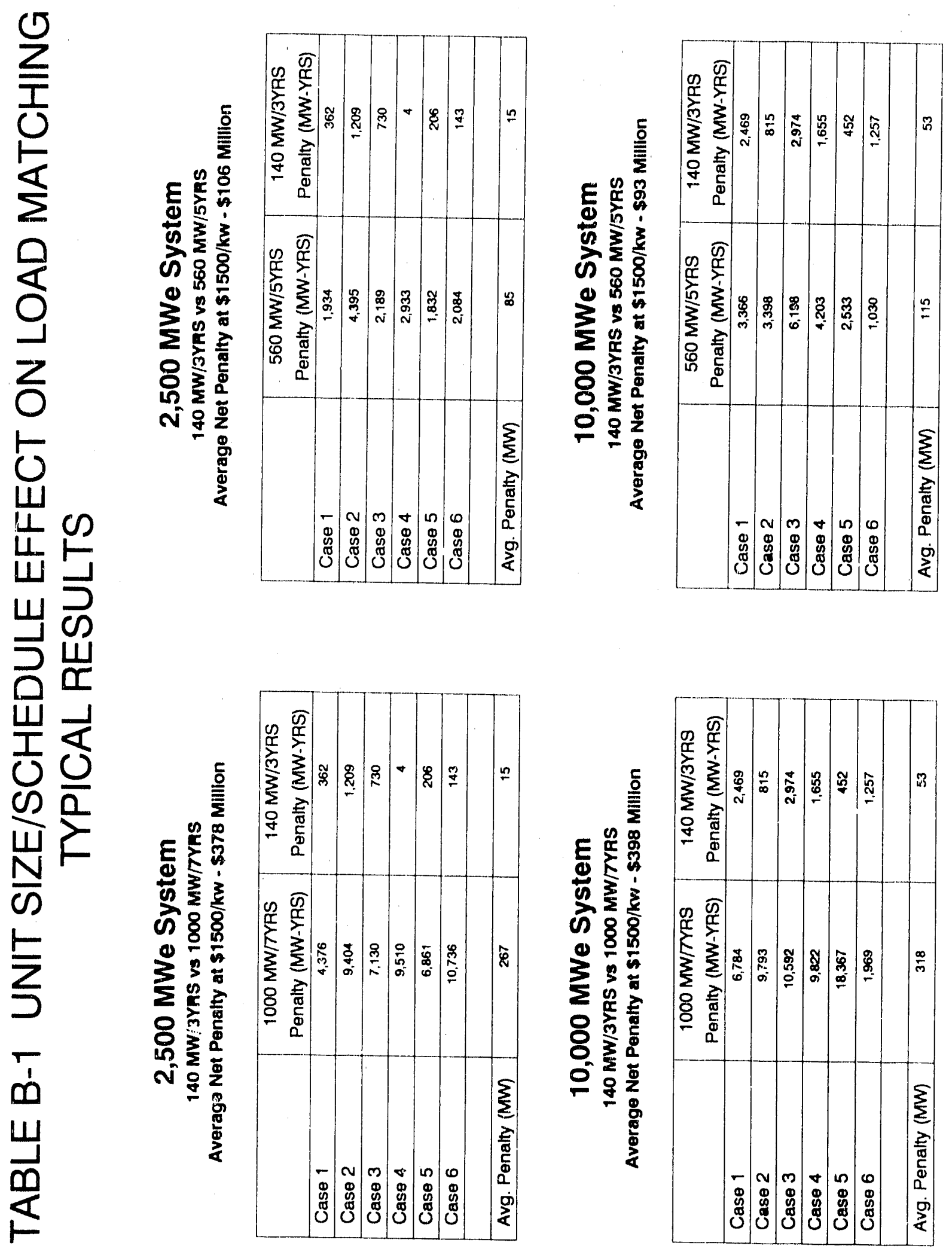




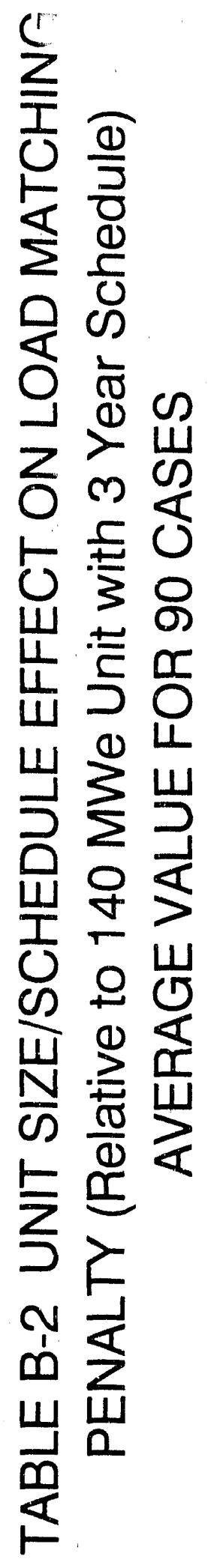

\begin{tabular}{|c|c|c|c|c|c|c|c|}
\hline $\begin{array}{l}\frac{\nexists}{\pi} \\
\frac{2}{\Phi} \\
0\end{array}$ & 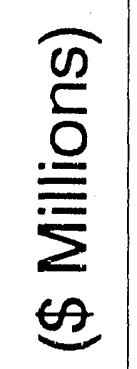 & 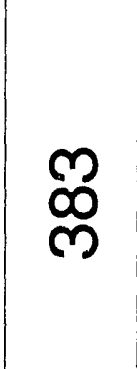 & $\frac{M}{F}$ & ల్ల & $\bar{m}$ & $\stackrel{\sim}{\sim}$ & ల్ల \\
\hline 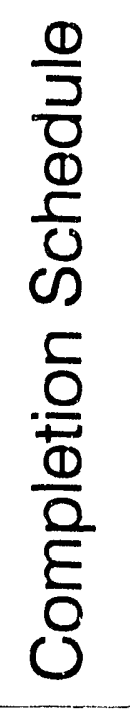 & $\begin{array}{l}\bar{n} \\
\bar{\pi} \\
\mathbb{d} \\
\Sigma\end{array}$ & $\Lambda$ & 10 & $\Lambda$ & 10 & $\Lambda$ & 10 \\
\hline \multirow[t]{2}{*}{ 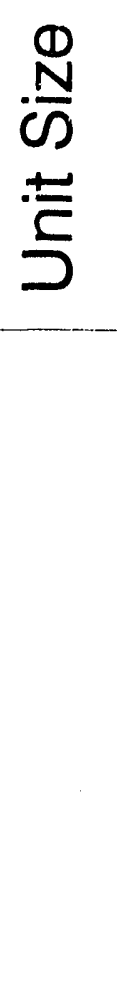 } & $\sum_{\sum}^{\mathbb{\Phi}}$ & $\underset{8}{8}$ & 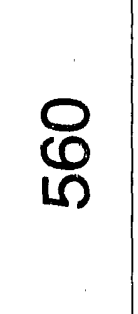 & $\begin{array}{l}8 \\
8 \\
-\end{array}$ & $\begin{array}{l}8 \\
6 \\
10\end{array}$ & $\underset{8}{8}$ & ర్ర \\
\hline & & 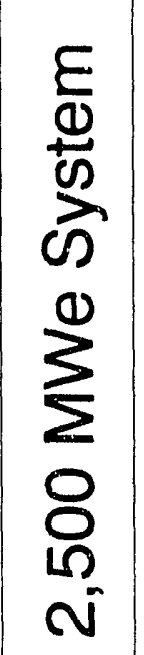 & 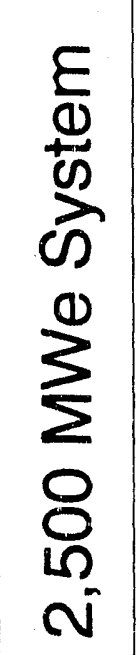 & 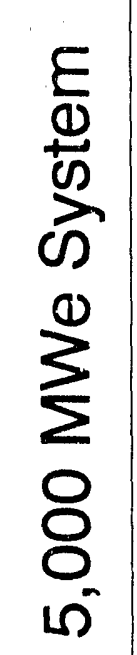 & 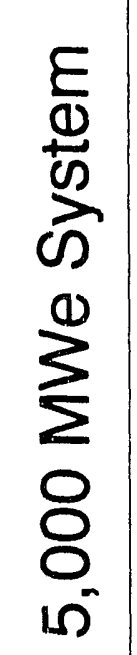 & 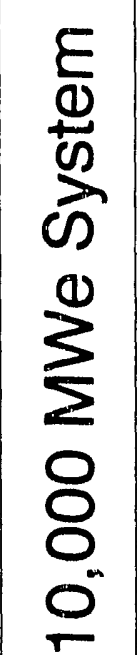 & 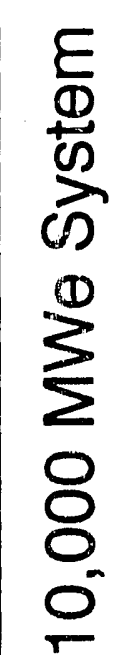 \\
\hline
\end{tabular}



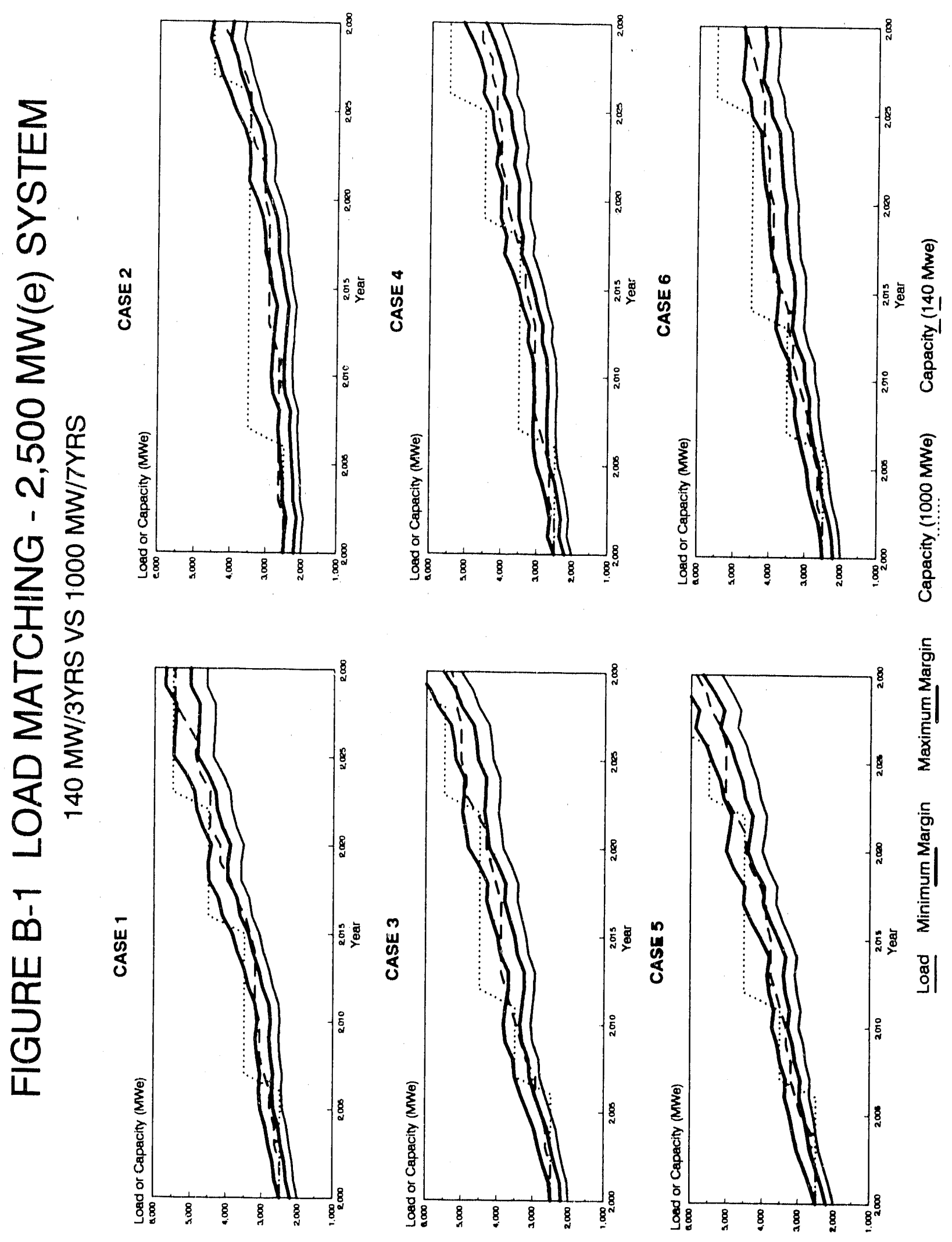


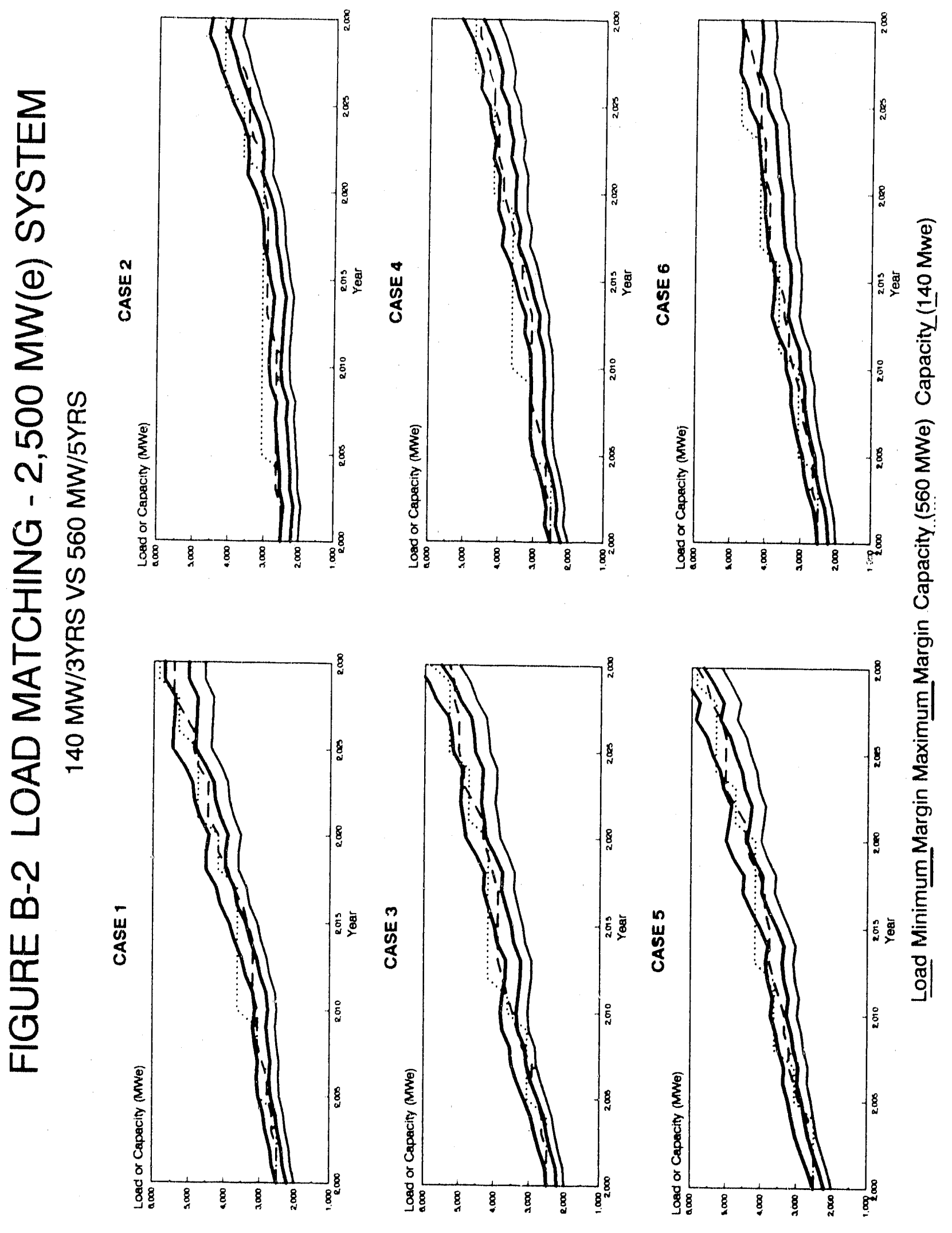




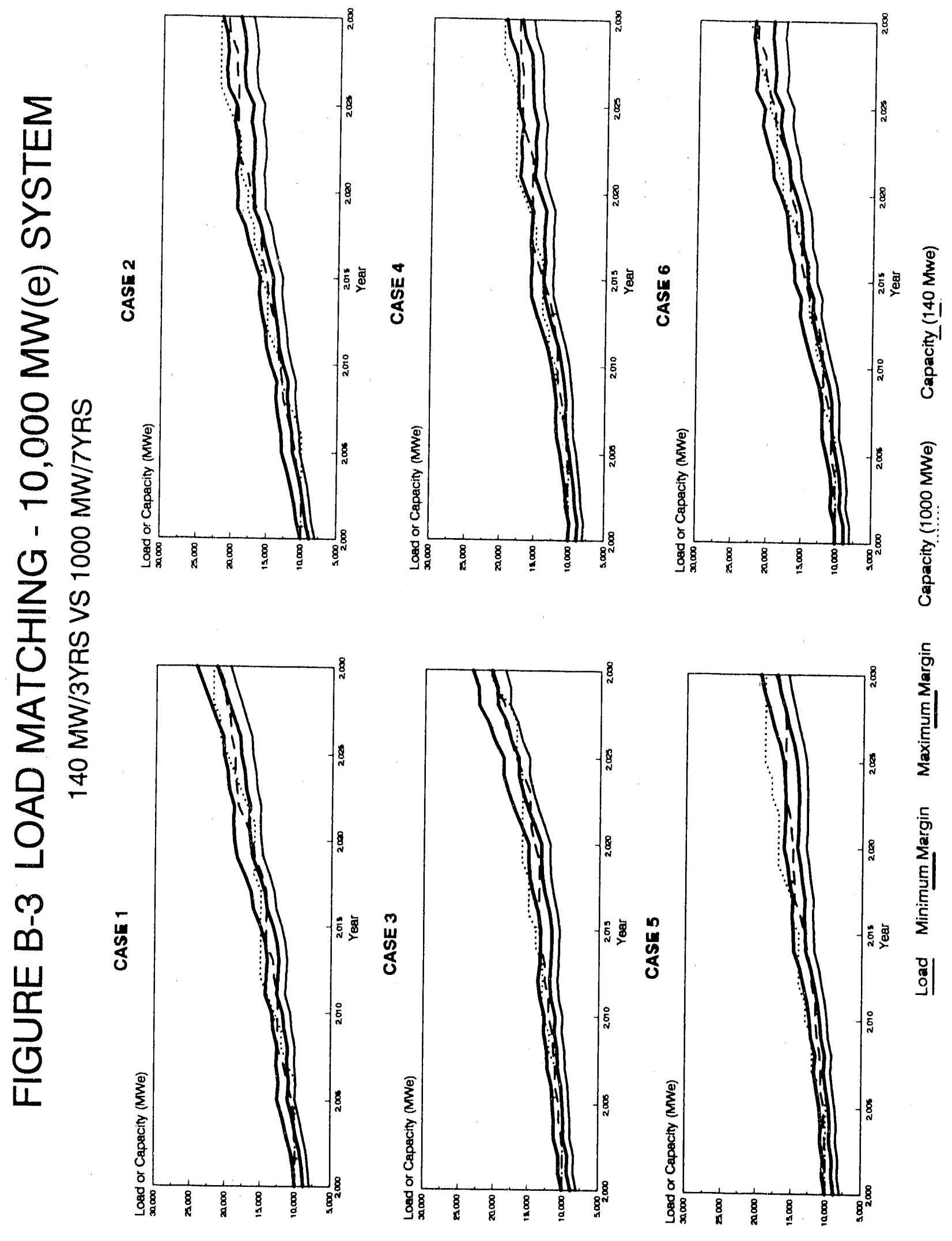




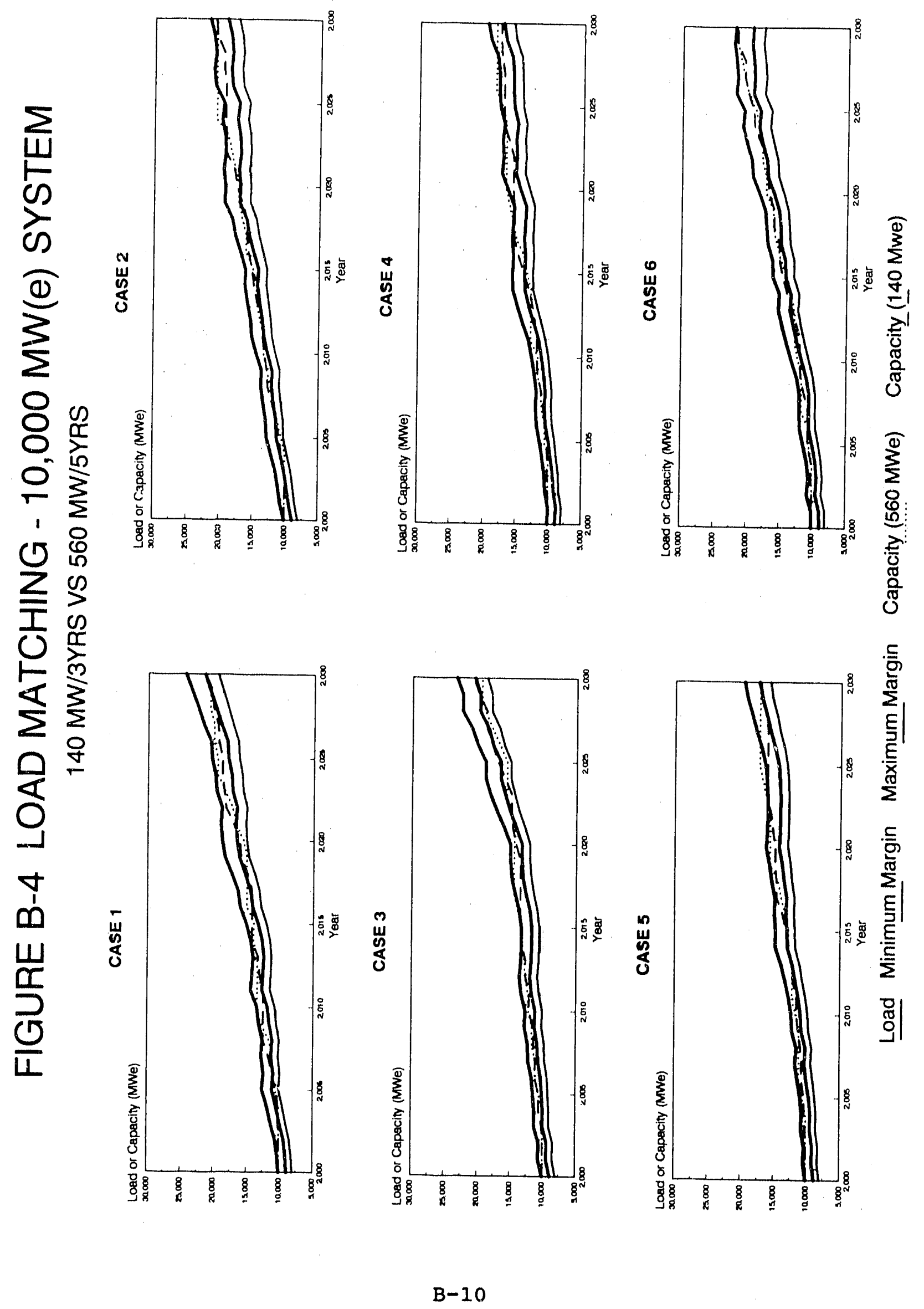


Per Plant Avoided Cost $=330 \times \frac{560}{5000}=\$ 37$ million

In other words, the avoided cost for the improved load matching capability would be about $\$ 40 \mathrm{million} / \mathrm{plant}$. 

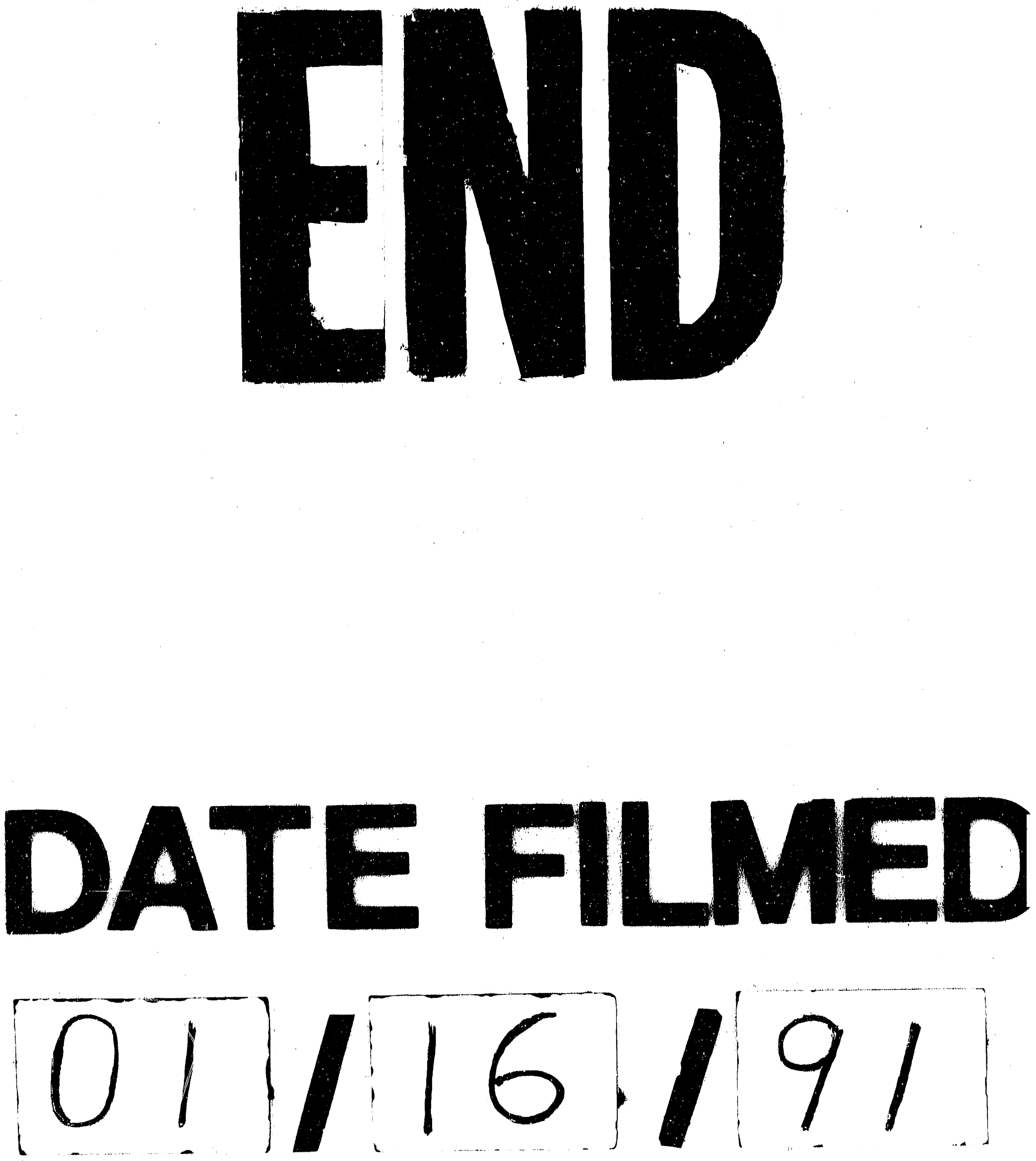
